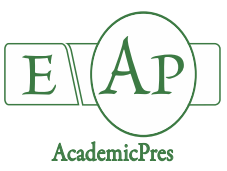

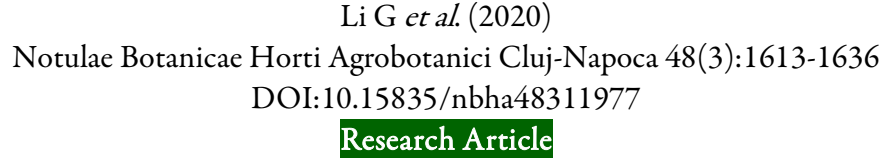

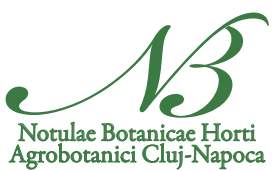

\title{
Understanding physiological and molecular mechanisms of Populus deltoides 'DanHongYang' tolerance to waterlogging by comparative transcriptome analysis
}

\section{Gang LI ${ }^{1,2 a}$, Qiusheng FU ${ }^{3 b}$, Zhongbin $\mathrm{LIU}^{4 c}$, Jiabao $\mathrm{YE}^{1}$, Weiwei $\mathrm{ZHANG}^{1}$, Yongling $\mathrm{LIAO}^{1}$, Feng XU ${ }^{1,2 *}$, Zhongcheng $\mathrm{ZHOU}^{3 *}$}

\author{
${ }^{1}$ Yangtze University, College of Horticulture and Gardening, Jingzhou 434025, Hubei, China; 15090754721@126.com; \\ yejiabao13@163.com; wwzhangchn@163.com; liaoyongling@yeah.net; xufeng@yangtzeu.edu.cn ("corresponding author) \\ ${ }^{2}$ Engineering Research Center of Ecology and Agricultural Use of Wetland, Ministry of Education; \\ ${ }^{3}$ Hubei Ecology Polytechnic College, Department of Forestry Ecology, Wuhan 430070, China; 835837548@qq.com; \\ 1806725680@qq.com (*corresponding author) \\ ${ }^{4}$ Wuhan University of Bioengineering, School of Horticulture and Landscape, Wuhan 430415, China; 418953176@qq.com \\ a,b,c These authors contributed equally to the work
}

\begin{abstract}
Populus deltoides 'DanHongYang' (DHY) was identified as a waterlogging-resistant cultivar in our previous study. Here, the phenotype, physiological features and transcriptome profiling of $P$. deltoides 'DHY' between the treatments of waterlogging and control were compared. Waterlogging treatment led to distinctly formation of adventitious roots from $P$. deltoides 'DHY' stems. The activities of ascorbate peroxidase and glutathione reductase significantly increased in the leaves of $P$. deltoides 'DHY' by waterlogging treatment. Comparative transcriptomic analysis showed that 2,447 and 9,465 differentially expressed genes (DEGs) were screened between the leaves and roots of $P$. deltoides 'DHY' under waterlogging and control, respectively. The KEGG analysis showed the most significantly up-regulated DEGs in the leaves and roots were enriched to the pathways of glycolyis and proline synthesis. Some genes involved in stress response, endogenous hormones, antioxidant system and adventitious root development in the waterlogged were identified to contribute to the waterlogging tolerance of $P$. deltoides ' $\mathrm{DHY}$ '. In addition, some candidate transcription factors such as RAP, NAC, WRKY, and bHLH were also found to be associated with the waterlogging tolerance of $P$. deltoides 'DHY'. These findings provided the insights into the physiological and molecular mechanisms underlying the tolerance of $P$. deltoides 'DHY' to waterlogging stresses.
\end{abstract}

Keywords: antioxidant system; adventitious root; energy metabolism; Populus deltoides; transcriptome; transcription factor; waterlogging stress

\section{Introduction}

Waterlogging stress has a significant negative effect on plant growth. Excessive soil moisture can disrupt the water balance of plants and significantly affect the morphology and metabolism of plants, restricting their growth (Irfan et al., 2010). Waterlogging puts severe stress on plant growth because excess water in the 
environment can deprive plants of basic needs (Jackson et al., 2009). The reduction in oxygen and carbon dioxide under waterlogging impedes photosynthesis and aerobic respiration, thereby limiting plant survival (Voesenek and Bailey-Serres, 2013). Waterlogging can also cause complex physiological, and biochemical changes, resulting in plant hypoxia (Tewari et al., 2016). This phenomenon can promote the increase in the redox potential between soil and plants and lead to the production of reactive oxygen species (Arbona et al., 2017), which induce lipid peroxidation and membrane damage of plant cells (Sairam, 2011).

A series of changes occurs in plants to protect them from waterlogging (Striker and Colmer, et al., 2017). The first response of morphological adaptation to waterlogging is the development of adventitious roots (Zhang et al., 2017). The expansion of adventitious roots is helpful to oxygenate underwater tissues by ventilating tissues, which make oxygen transfer from leaves to roots possible (Colmer et al., 2003). For example, adventitious root primordium is formed under waterlogged adaptive tissues in rice, and the interaction between auxin and ethylene causes adventitious roots in rice (Coudert et al., 2010). Ethylene response factor ERF-VII is hypoxic sensitive in regulating waterlogging adaptation (Licausi et al., 2011). When plants are unable to perform aerobic respiration, the cells' vitality and energy supply are maintained via anaerobic, glycolytic, and fermentation when plants are unable to perform aerobic respiration (Bailey-Serres and Voesenek 2008).

Poplar grows fast and has strong water tolerance. It has become the main afforestation tree species in waterlogged areas (Du et al., 2012). In our previous work, we evaluated the waterlogging tolerance of several poplar cultivars and demonstrated that the cultivar $P$. deltoides 'DanHongYang' (DHY) could withstand longterm waterlogging stress (Zhou et al., 2019). However, the physiological and molecular mechanisms of this Poplar cultivar's tolerance to waterlogging remain unclear. In this study, we constructed four independent cDNA libraries of the leaves and roots of $P$. deltoides ' $\mathrm{DHY}$ ' under waterlogging and control conditions. We also performed transcriptome sequencing as well as compared and analyzed physiological indicators comprehensively. Differential expression genes (DEGs) related to adventitious root germination, antioxidant system, photosynthesis, endogenous hormone metabolism pathway, and waterlogging tolerance were screened, and their roles in waterlogging tolerance were identified. Our data provided the insights into the physiological and molecular mechanisms of waterlogging tolerance $P$. deltoides 'DHY'.

\section{Materials and Methods}

\section{Materials}

The experimental site was located in the botanical garden of Yangtze University in Jingzhou, Hubei, China (around N30.35, E112.14). The experimental materials were 1-year old poplar cuttings $P$. deltoides 'DHY'. Planting of the cuttings was started on March 20, 2018. The stem cuttings were planted in plastic flowerpots (10 cm in inner diameter and $25 \mathrm{~cm}$ in depth). The culture medium was vermiculite, coconut shell powder and perlite, uniformly mixed with the ratio of 5:3:2 and placed in the greenhouse for seedling cultivation, one cutting seedlings of each pot. During this period, the cultivation and management measures were undertaken to maintain consistency until the end of the waterlogging. The cutting seedlings that reached at uniform growth of about $90 \mathrm{~cm}$ height were selected for waterlogging treatment on July, 2018. The experiment was designed as a random group, four of each group with 3 replications, and control and waterlogging were treated with 36 pots. The waterlogging treatment was such that the water surface was about $15 \mathrm{~cm}$ above the soil surface, and water was replenished daily to keep the water level constant. Control plants were watered every evening to maintain the soil moisture content at $60-80 \%$ of the maximum field water capacity after the first watering. During this period of the experiment, plant morphological characteristics were recorded with taking photos regularly. After waterlogging for 65 days, the mature leaves and roots were harvested and immediately frozen in liquid nitrogen to store at $-80{ }^{\circ} \mathrm{C}$. The frozen materials were used to determine their physiological and biochemical indices and transcriptome sequencing. Physiological and biochemical indices were determined with 4 biological samples, and the leaves control: DPLC1, DPLC2, 
DPLC3, waterlogging treat: DPLF1, DPLF2, DPLF3) and roots (control: DPRC1, DPRC2, DPRC3, waterlogging treat: DPRF1, DPRF2, DPRF3） samples used for sequencing with three biological replicates per treatment.

\section{Physiological index measurement}

After 65 days of submergence treatment, the roots, stems, and leaves of the plants were separately harvested and their fresh biomass were measured. Chlorophyll content were determined according to the method of Wellburn (1994). Soluble sugar content was determined using anthrone colorimetric method (Moustakas et al., 2011). The MDA content was extracted using thiobarbituric acid (TBA) reagent and boiled at $100^{\circ} \mathrm{C}$ for $20 \mathrm{~min}$ as previously described by Yang (2009). Proline content was estimated using described method with L-proline as standard (Yang et al., 2011). The activities of antioxidant enzymes (T-SOD, CuZnSOD, POD, CAT, APX, soluble-Protein and GR) were determined according to the instructions of corresponding kits (NanjingJiancheng Biotech Co., Nanjing, China).

The photosynthesis parameters of poplar leaves were determined from 09:00 to 12:00 $\mathrm{hr}$ (solar time) using a portable open system infrared gas analyzer (LI-6400, LI-COR Inc., Lincoln, NE, USA). The chlorophyll fluorescence parameters were determined using a fluorometer with a modulated pulse (MINIPAM) (Walz, Effeltrich, Germany) on the same leaflets used for the leaf gas exchange parameters measurement. Determination parameters include the maximum emitted fluorescence $(\mathrm{Fm})$. The maximum fluorescence $(\mathrm{Fm}$ '), the maximum photosystem II (PSII) photochemical efficiency ( $\mathrm{Fv} / \mathrm{Fm})$, the electron transport rate, the quantum yield of electron transport (Yield) and the photochemical (qP). Before measuring, the leaf darkadapted for $30 \mathrm{~min}$, Specific operating steps are completed according to the method of Nascimento (Nascimento et al., 2018).

\section{Library construction and transcriptome sequencing}

The total RNA of leaves and roots was extracted using a TAKARA MIniBEST Plant RNA Extraction Kit in accordance with the manufacturer s instructions. RNA samples were tested for degradation and impurities by using $1 \%$ agarose electrophoresis. Sample purity was measured using a NanoDrop 2000 microspectrophotometer (IMPLEN, CA, USA), and the integrity and concentration of the RNA sample were detected using an Agilent 2100 RNA Nano 6000 Assay Kit (Agilent Technologies, CA, USA). Sequencing libraries were obtained using the NEBNext1Ultra RNA Library Prep Kit for Illumina* (NEB, USA) in accordance with the manufacturer $s$ instructions and the construction of 12 cDNA libraries were completed. The concentration and quality of these libraries (12 cDNA) were tested using Agilent 2100 and Qubit 2.0, respectively. The Illumina HiSeq 2500 sequencing platform (Baimaike, Beijing) was used to sequence 12 cDNA libraries from the control / waterlogging leaves and roots. The original sequence data was obtained by Illumina HiSeq sequencing. High-quality reads (clean reads) were obtained by removing low-quality reads, joint-pollution reads and reads with $\mathrm{N}$ ratios greater than $5 \%$. HISAT v2.0.4 software with default parameters was used to map clean reads filtered from original Reads to the Populus trichocarpa reference genome database (Tuskan Grabherr et al., 2006). All clean reads of the 12 libraries were obtained by assembling full-length transcriptional sequences using Trinity software and the DE Bruijn method (Grabherr et al., 2011). Transcriptome sequences are annotated with trinotate, and functional annotations are mainly performed using databases, including PFAM, Nr, Swissprot, GO, COG and KEGG annotations.

\section{DEG analysis}

RPKM value were used to represent the expression abundance of reads corresponding to Genes. In this study, we used TopHat 2 to compare the treatment group and the control group with the reference group and selected $\mid \log 2$ Ratio $\mid>1$ and $Q<0.05$ genes as DEGs (Kim et al., 2013). Enrichment analysis of DEGs was analyzed using the GO and KEGG databases to obtain a detailed description of the DEGs during seed 
germination. The DEGs were clustered with $\mathrm{p}<0.05$, which indicated that the cluster distribution was significant under the comparison between waterlogging and control.

\section{Statistical analysis of data}

Data were analyzed using Excel and SPSS (SPSS, Chicago, IL, USA) by ANOVA followed by Turkey's significant difference test at $\mathrm{p}<0.05$. All data had three biological repeats.

\section{Results}

\section{Effects of waterlogging on morphology, physiology in P. deltoides 'DHY'}

The growth of poplar was significantly inhibited after waterlogging (Figure 1A-D and Figure 6B). A large number of roots died with some new lateral roots (Figure 1E), and a part of adventitious roots were generated little by little from the stems compared with the control (Figure 1F and 1G). Simultaneously, the ratio of chlorophyll a, chlorophyll b, carotenoid, and chlorophyll $\mathrm{a} / \mathrm{b}$ in the leaves of $P$. deltoides 'DHY' were significantly lower than those of the control under waterlogging (Figure $1 \mathrm{H})$.

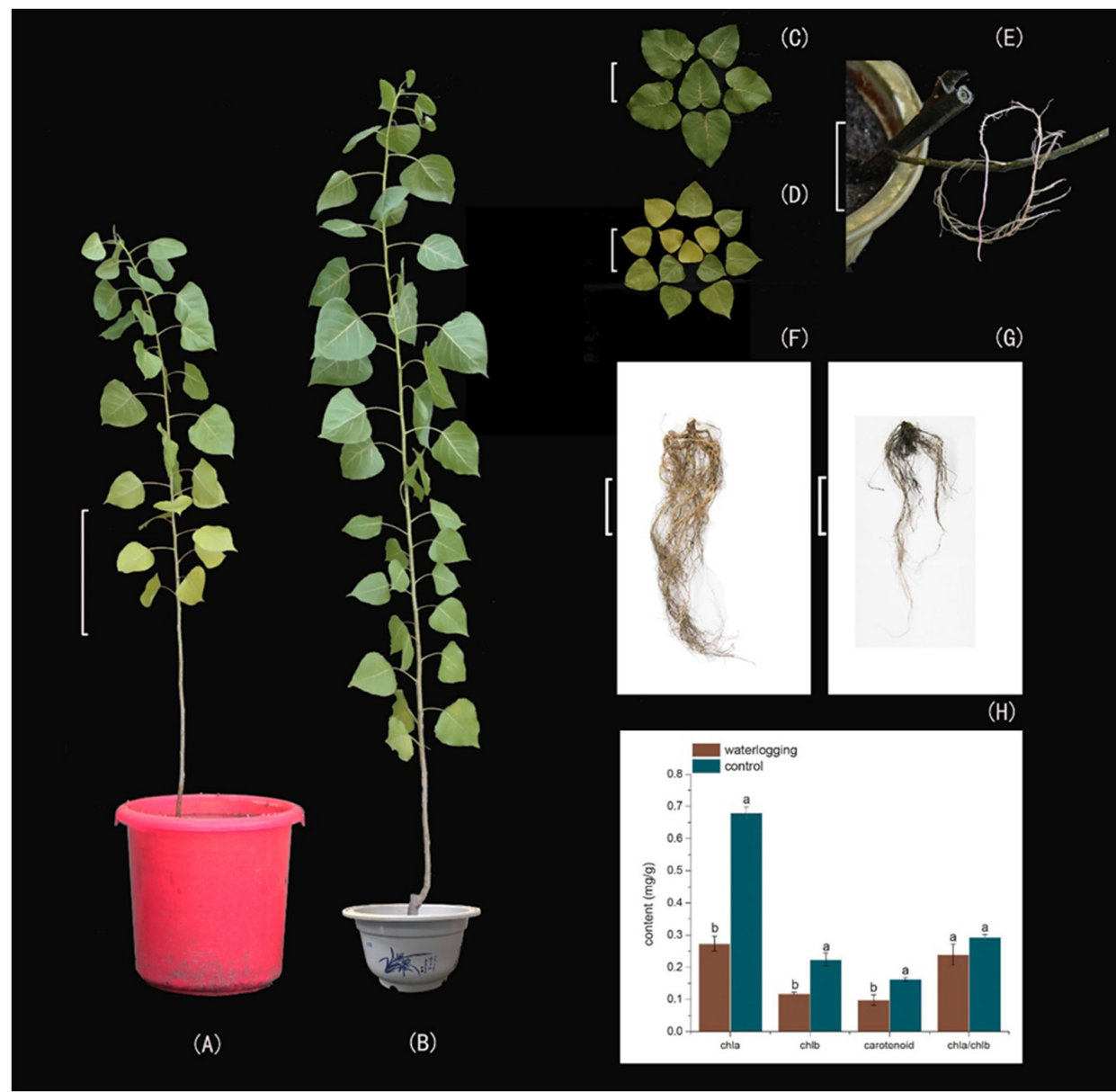

Figure 1. Effects of waterlogging on phenotype of leaf and root and chlorophyll content in P. deltoides 'DHY'. The external morphology of DHY (A, D, G) under waterlogging treatment and (B, C, F) under normal growth condition. The scale bars of the whole poplar tree are $20 \mathrm{~cm}$, and the scale bars of leaves is $10 \mathrm{~cm}$. The emergence of adventitious roots $(\mathrm{E})$, the scale is $5 \mathrm{~cm}$. Comparison of chlorophyll content under waterlogging treatments $(\mathrm{H})$ 


\section{Effects of waterlogging on antioxidant enzyme activities in $P$. deltoides ' $D H Y$ '}

The activities of antioxidant enzymes including ascorbate peroxidase (APX), glutathione reductase (GR), catalase (CAT), peroxidase (POD), total superoxide dismutase (T-SOD), CuZn superoxide dismutase (CuZn-SOD) in the leaves of $P$. deltoides ' $\mathrm{DHY}$ ' changed to varying degrees after $65 \mathrm{~d}$ of waterlogging (Table 1). The activities of CAT and GR were significantly higher in waterlogged poplars than in the control (Table 1). The activities of APX, POD, T-SOD, CuZn-SOD were significantly lower in the waterlogged poplars than in the control. In addition, malondialdehyde (MDA) and soluble protein content were significantly increased compared with the control.

Table 1. Comparison of physiological and biochemical parameters in popular leaves in response to waterlogging stress

\begin{tabular}{|c|c|c|c|c|c|c|c|c|}
\hline $\begin{array}{c}\text { Physiological and } \\
\text { biochemical } \\
\text { parameters }\end{array}$ & $\begin{array}{c}\text { APX } \\
\text { activity } \\
(\mathrm{U} / \mathrm{g} / \mathrm{min})\end{array}$ & $\begin{array}{c}\mathrm{GR} \\
\text { activity } \\
(\mathrm{U} / \mathrm{g} / \mathrm{min})\end{array}$ & $\begin{array}{l}\text { CAT activity } \\
(\mathrm{U} / \mathrm{mg} / \mathrm{min})\end{array}$ & $\begin{array}{l}\text { POD activity } \\
(\mathrm{U} / \mathrm{mg} / \mathrm{min})\end{array}$ & $\begin{array}{c}\text { T-SOD } \\
\text { activity } \\
(\mathrm{U} / \mathrm{g} / \mathrm{min})\end{array}$ & $\begin{array}{l}\mathrm{CuZnSOD} \\
\text { activity } \\
(\mathrm{U} / \mathrm{g} / \mathrm{min})\end{array}$ & $\begin{array}{l}\text { MDA } \\
\text { content } \\
(\mathrm{mg} / \mathrm{g})\end{array}$ & $\begin{array}{l}\text { Soluble } \\
\text { protein } \\
(\mathrm{mg} / \mathrm{ml})\end{array}$ \\
\hline $\begin{array}{c}\text { Control } \\
\text { Waterlogging } \\
\text { treatment }\end{array}$ & $\begin{array}{c}1.95 \pm 0.26 \\
\mathrm{~b} \\
3.33 \pm 0.15 \\
\mathrm{a}\end{array}$ & $\begin{array}{c}18.56 \pm 2.9 \\
2 \mathrm{~b} \\
32.38 \pm 7.0 \\
1 \mathrm{a}\end{array}$ & $\begin{array}{c}44.75 \pm 3.89 \\
a \\
22.92 \pm 1.34 \\
b\end{array}$ & $\begin{array}{c}49.35 \pm 7.13 \\
a \\
26.29 \pm 6.38 \\
b\end{array}$ & $\begin{array}{c}1070.85 \pm 4 \\
9.27 \mathrm{a} \\
616.30 \pm 73 \\
28 \mathrm{~b}\end{array}$ & $\begin{array}{c}1216.06 \pm \\
22.55 \mathrm{a} \\
523.84 \pm 3 \\
5.31 \mathrm{~b}\end{array}$ & $\begin{array}{c}4.22 \pm 0.3 \\
3 \mathrm{~b} \\
6.36 \pm 0.6 \\
1 \mathrm{a}\end{array}$ & $\begin{array}{c}0.39 \pm 0.02 \\
\mathrm{~b} \\
0.66 \pm 0.08 \\
\mathrm{a}\end{array}$ \\
\hline
\end{tabular}

Data are mean \pm SE from biological experiments $(n=3)$. Data with the different letters are significantly different by Turkey's significant difference test at $\mathrm{p}<0.5$.

Note: APX: aseorbateperoxidase; GR : glutathione reductase; CAT: catalase; POD: Peroxidase; T-SOD: Total Superoxide Dismutase; CuZnSOD: CuZn Superoxide Dismutase; MDA : Malondialdehyde.

Sequence alignment and mapping to the reference genome

A total of $12 \mathrm{cDNA}$ libraries were sequenced using Illumina HiSeq, and the sequencing data were stored in NCBI (SRR10828697-SRR10828686). The Q30 of the 12 samples exceeded 94\% (Supplementary Table 1). A total of 42,569 genes were obtained by using Trinity software for de novo assembly. The average lengths of genes and N50 were 2,458 and 1,732 bp, respectively. The total length of 4,435 genes was more than $400 \mathrm{bp}$, and 13,146 genes were over 2,000 bp (Supplementary Table 2). The gene sequences of the samples were compared with commonly used functional databases using Trinotate (Supplementary Table 3). The comparison with the NR database obtained 42,017 annotated genes. The comparison with KOG, Swiss-Prot, PFAM, COG, GO, KEGG, and eggNOG databases obtained 20,756, 29,154, 398, 14,329, 25,089, 12,982, and 33,486 annotated genes, respectively. Moreover, 14,329 and 25,089 genes were annotated into the 25 COG and 50 GO pathways, respectively, in the transcriptome database of $P$. deltoides 'DHY' (Supplementary Figure 1). These above results indicate that the assembly quality of sequencing data meets the requirements of transcriptome analysis.

\section{Comparative analysis of DEGs}

The total number of genes upregulated in the leaves and roots of $P$. deltoides ' $\mathrm{DHY}$ ' under waterlogging conditions were 920 and 4,283, whereas 1,527 and 5,182 were downregulated, respectively (Figure 2A). The leaves and roots of $P$. deltoides 'DHY' under waterlogging were 1,426 and 8,444 genes specifically expressed, and 1021 commonly expressed in the leaves and roots of waterlogging $P$. deltoides 'DHY', respectively, compared with the control (Figure 2B). A total of 750 DEGs were upregulated in the leaves of $P$. deltoides 'DHY', 4,113 DEGs upregulated in the roots, and 170 DEGs upregulated in the roots and leaves under waterlogging conditions (Figure 2C). A total of 1,097 DEGs were downregulated in the leaves of $P$. deltoides 'DHY', 4,752 DEGs downregulated in the roots, and 430 DEGs commonly downregulated in the roots and leaves under waterlogging conditions (Figure 2D). 
(A)

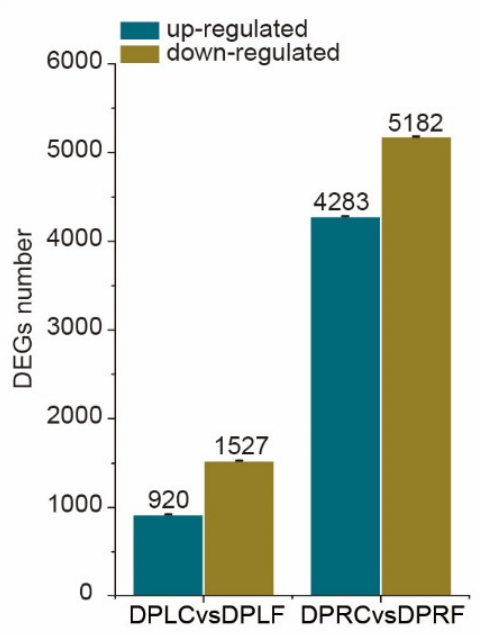

(C)

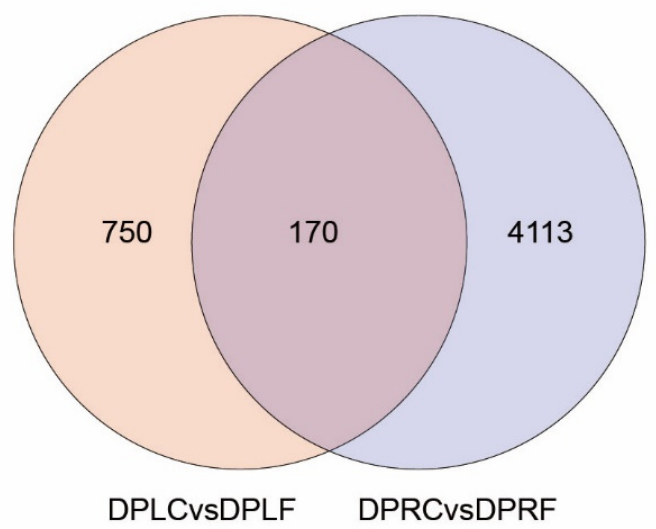

(B)

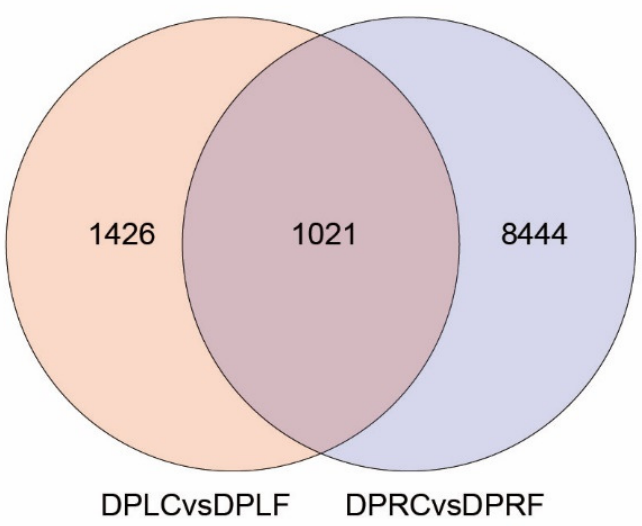

(D)

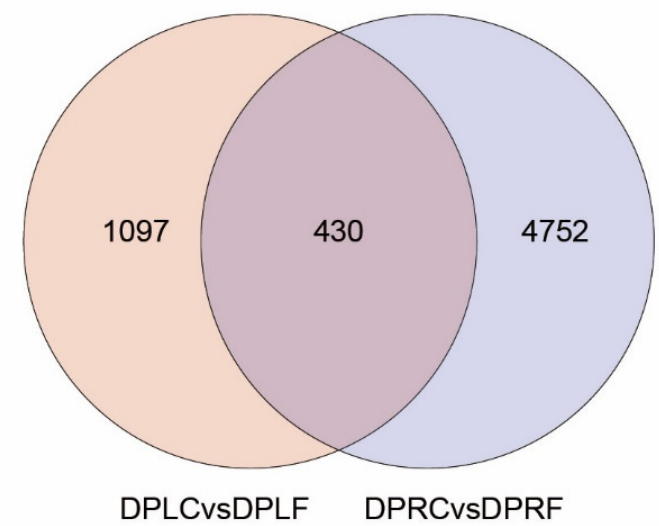

Figure 2. Statistical analysis of differentially expressed genes (DEGs) during waterlogging in $P$. deltoides 'DHY'. (A) Statistical analysis of up/down-regulated DPLC vs DPLF and DPRC vs DPRF group. (B) Venn diagram of all DEGs. (C) Venn diagram of up-regulated genes. (D) Venn diagram of down-regulated genes

\section{DEGs of KEGG analysis}

KEGG enrichment analysis of DEGs was performed in this study to assess the response mechanism of P. deltoides 'DHY' under waterlogging stress. As shown in the Figure 3A, a total of 518 DEGs were enriched to 105 pathways in the leaves of control (DPLC) versus the leaves of waterlogging treatment (DPLF) group, mainly including photosynthesis, photosynthesis-antenna protein, glycolysis, amino acid biosynthesis, starch and sucrose metabolism, peroxisome, pentose phosphate pathway, and pyruvate metabolism. A total of 1,936 DEGs were enriched to 126 pathways, including amino acid biosynthesis, starch and sucrose metabolism, ascorbic acid and uronic acid metabolism, glycolysis, and fatty acid degradation in the roots of control (DPRC) versus the roots of waterlogging treatment (DPRF) group (Figure 3B). Furthermore, 305 and 716 DEGs were screened from leaves and roots, respectively, by further transcriptome analysis which may be related to waterlogging tolerance (Figure 3C and D). The cluster analysis of the expression amount of DEGs showed that 117 and 271 were upregulated and 188 and 445 were downregulated DEGs in the leaves and roots, respectively. 
(A)

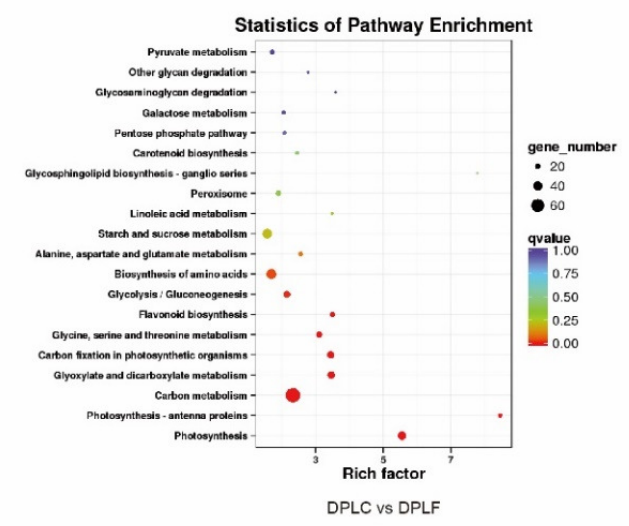

(C)

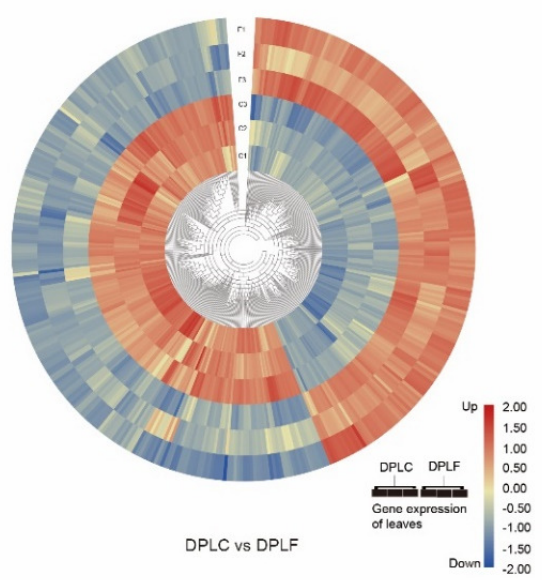

(B)

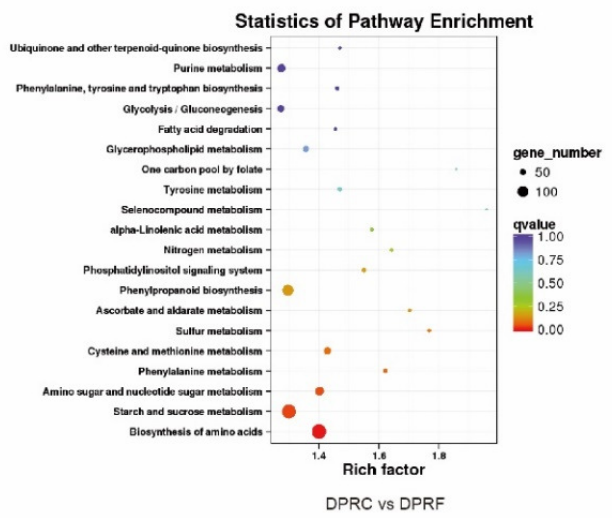

(D)

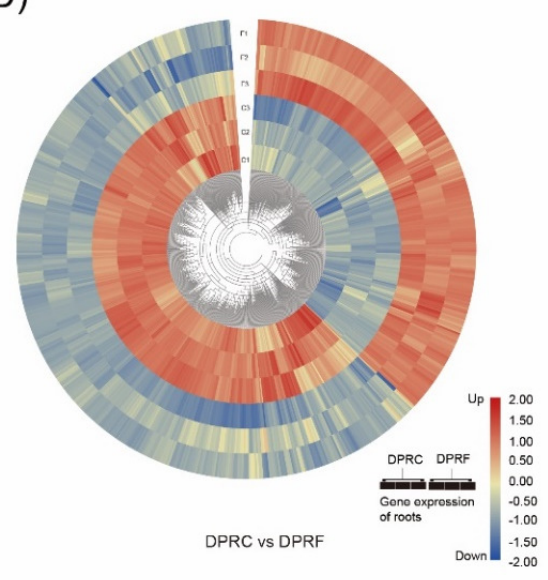

Figure 3. Functional annotations of genes of leaves and roots transcriptome in in P. deltoides 'DHY' and DEGs of Expression profile analysis in $P$. deltoides leaves and roots under waterlogging stress. (A, B) KEGG pathway enrichment of differentially expressed genes (DEGs) Only top 20 enriched KEGG pathways were showed respectively leaves and roots. (C) DEGs related to waterlogging tolerance in leaves. (D) DEGs related to waterlogging tolerance in roots

The $\mathrm{X}$-axis shows the enrichment factor. A high $\mathrm{q}$-value is represented by green and a low $\mathrm{q}$-value is represented by red $(\mathrm{q}<0.05)$. Bubble size indicates DEG number (increases with DEG number)

\section{DEGs related to adventitious root primordia initiation under waterlogging stress}

A large number of adventitious roots appeared on the stems of the surface of the waterlogged roots of $P$. deltoides 'DHY' after $65 \mathrm{~d}$ of waterlogging treatment (Figure 1E). Simultaneously, 14 DEGs were found to be related to adventitious root germination in waterlogged roots (Figure 4A). The expression of Protein Root Initiation Defective 3 (RID3), Aberrant root formation protein 4 (ALF4), Protein Lateral root primordium 1.1 (LRP1.1) and Protein Short-root 1 (SHR1) genes were significantly upregulated, suggesting that these genes may be involved in the formation of adventitious roots of poplars under waterlogging stress. 
(A)

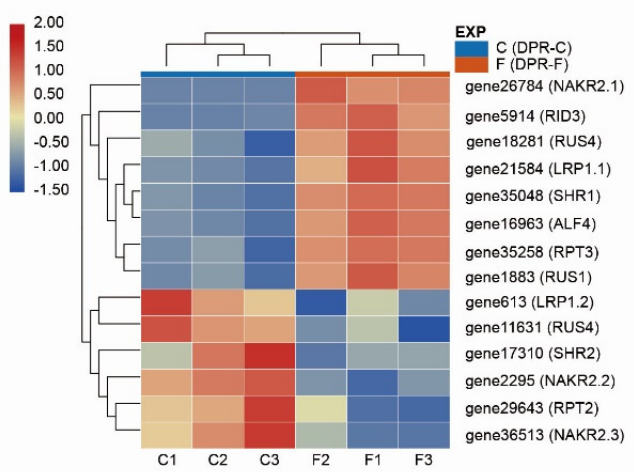

(B)

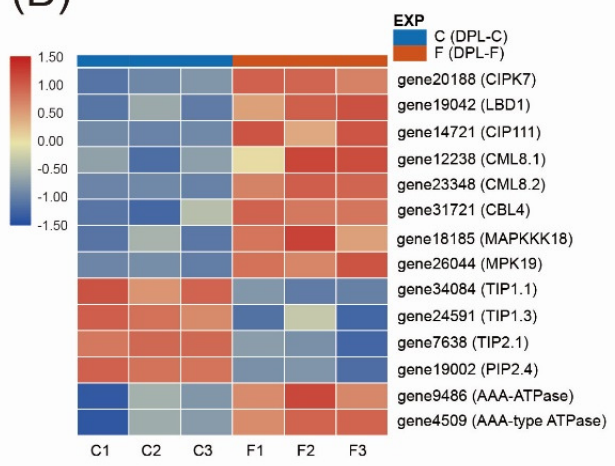

(D)

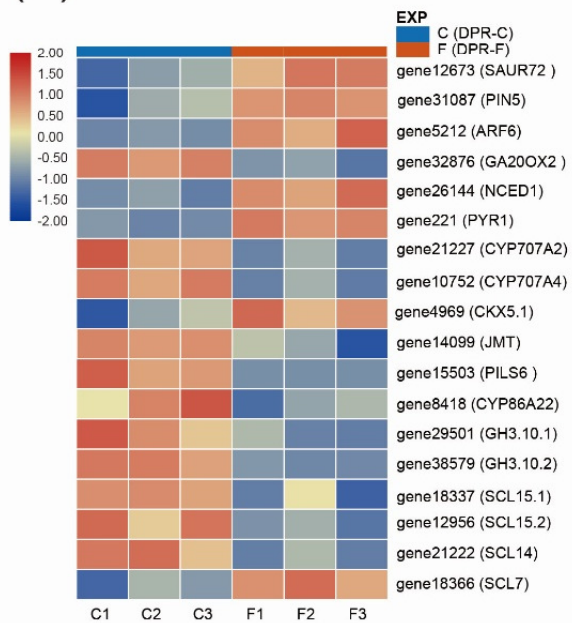

(C)

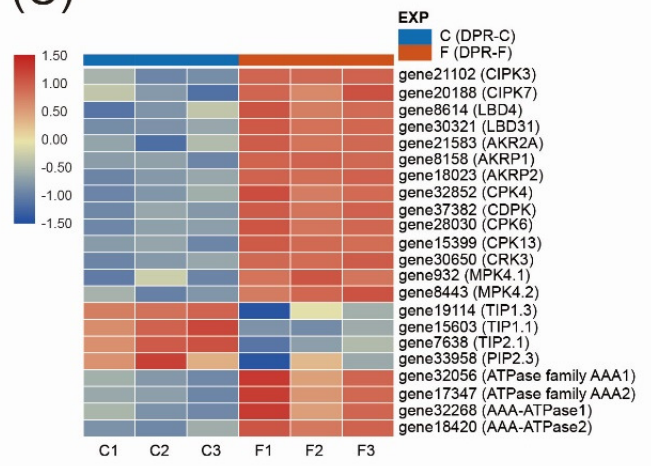

(E)

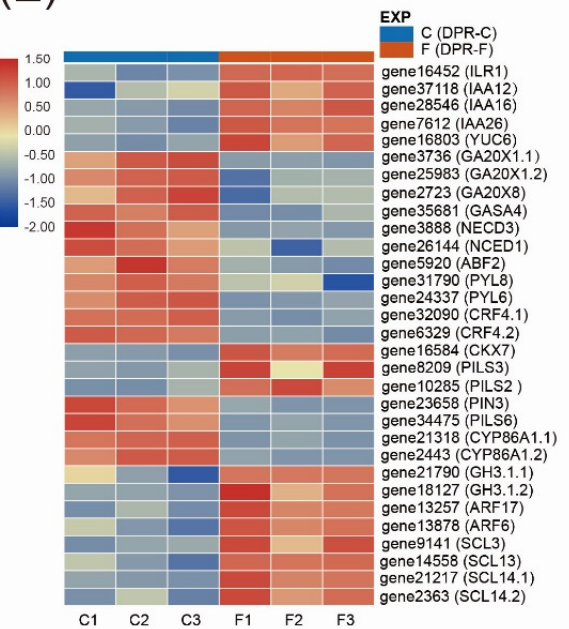

Figure 4. DEGs related to adaptation and adventitious root primordia initiation under waterlogging stress in P. deltoides 'DHY'. (A) Heatmap analysis of DEGs in the roots related to adventitious root primordia initiation. (B) Heatmap analysis of DEGs in leaves of $P$. deltoides 'DHY' stress response. (C) Heatmap analysis of DEGs in the roots related to stress response. (D) Heatmap analysis of DEGs in leaves of $P$. deltoides 'DHY' related to hormone response and biosynthesis. (E) Heatmap analysis of DEGs in roots of $P$. deltoides related to hormone response and biosynthesis

The sample names are showed at the bottom. The change in expression level is represented by the change in color, blue indicates a lower expression level and red indicates a higher expression level 


\section{DEGs related to stress response under waterlogging stress}

A total of 14 and 30 DEGs were related to stress response in roots and leaves, respectively (Figure 4B and $\mathrm{C}$ ). The DEGs upregulated in the leaves of $P$. deltoides ' $\mathrm{DHY}$ ' under waterlogging stress included CBLinteracting serine / threonine-protein kinase 7 (CIPK7), LOB domain-containing protein (LBD1), calmodulin-interacting protein 111 (CIP111), 3 calmodulin-like protein (CML) and mitogen-activated protein kinase kinase kinase 18 (MAPKKK18) genes. Moreover, 2 CIPK, 2 LBD, 3 Ankyrin repeat domaincontaining protein (AKR), Calcium-dependent protein kinase SK5 (CDPK), 2 Mitogen-activated protein kinase (MPK), and 5 Calcium-dependent protein kinase (CPK) genes were upregulated in the roots under waterlogging conditions. In addition, the expression of aquaporin genes in the leaves and roots of $P$. deltoides 'DHY' was downregulated under waterlogging stress.

\section{DEGs related to hormonal regulation of AR emergence under waterlogging stress}

A total of 18 and 31 DEGs were related to hormones in the leaves and roots of control and waterlogging P. deltoides ' $\mathrm{DHY}$ ', respectively (Figure $4 \mathrm{D}$ and $\mathrm{E}$ ). The expression levels of auxin-responsive protein SAUR72 (SAUR72), Protein Pin-likes 6 (PILS6), auxin response factor 6 (ARF6), and auxin efflux carrier component 5 (PIN5) in the leaves were significantly upregulated, but the expression levels of Gibberellin (GA), 9-cisepoxycarotenoid dioxygenase (NCED), abscisic acid receptor 1 (PYR1), 2 Abscisic acid 8\&apos-hydroxylase 2 (CYP707A), Cytokinin dehydrogenase 5 (CKX5), Jasmonate O-methyltransferase (JMT), Cytochrome P450 86A22 (CYP86A22), and 2 indole-3-acetic acid-amido synthetase (GH3.10) genes were significantly downregulated in DPLF group. The expression of other 3 SCLs was downregulated except for SCL7 in DPLF group. In DPRF group, the expression levels of IAA-amino acid hydrolase (ILR1), 3 Auxin-responsive protein (IAA), Indole-3-pyruvate monooxygenase YUCCA6 (YUC6), CKX7, 2 GH3.1, 2 PILS and 3 Scarecrow-like protein (SCL) genes were significantly upregulated, while the gene expression levels of 4 GAs, ABSCISIC ACID-INSENSITIVE 5-like protein 5 (ABF2), 2 Abscisic acid receptor PYL (PYL), 2 NCED, 2 Ethyleneresponsive transcription factor CRF4 (CRF4) and 2 Cytochrome P450 86A1 (CYP86A1) genes were significantly decreased.

The expression levels of 30 DEGs associated with ethylene synthesis transduction in the roots of waterlogging treated $P$. deltoides 'DHY' were significantly lower in than those in the control (Figure 5), including aspartate kinase (LYSC), Bifunctional aspartokinase / homoserine dehydrogenase 1 (THRA), aspartate-semialdehyde dehydrogenase (ASD), cystathionine gamma-synthase (METB), homocysteine Smethyltransferase (MMUM), 5-methyltetrahydropteroyltriglutamate--homocysteine methyltransferase (METE), adenosylhomocysteinase (AHCY), DNA (cytosine-5)-methyltransferase 1 (DCM), Sadenosylmethionine synthetase (METK), 1-aminocyclopropane-1-carboxylate synthase (ACS) and aminocyclopropanecarboxylate oxidase (ACO ) under waterlogged treatment.

\section{DEGs related to sugar metabolism under waterlogging stress}

The soluble sugar content in the leaves of $P$. deltoides ' $\mathrm{DHY}$ ' was significantly higher than that of the control after $65 \mathrm{~d}$ of waterlogging (Figure 6A). The RNA-seq results showed 22 and 38 DEGs in the leaves and roots of the control and waterlogged poplar, respectively (Figure 6C and D). Furthermore, 14 and 25 DEGs significantly upregulated in the leaves and roots, respectively (Figure 7A and $\mathrm{B}$ ). The expression of ENO, glyceraldehyde 3-phosphate dehydrogenase (GAPDH), phosphoglycerate kinase (PGK), pyruvate kinase (PK), triosephosphate isomerase (TPI), fructose-bisphosphate aldolase (ALDO), hexokinase (HK), aldose 1epimerase (GALM), 6-phosphofructokinase 1 (PFK), diphosphate-dependent phosphofructokinase (PFP) and 2,3-bisphosphoglycerate-dependent phosphoglycerate mutase (PGMA) were significantly higher expressed in roots and leaves, whereas PGM was only significantly upregulated in roots. Moreover, 9 and 21 DEGs of genes were involved in glucose metabolism pathways in the leaves and roots, respectively. The

expression levels of isocitrate dehydrogenase (IDH)s, malate dehydrogenase (CMDH), pyruvate decarboxylase (PDC) and alcohol dehydrogenase (ADH1) were significantly upregulated in the leaves of $P$. deltoides 'DHY', 
and the expression levels of malate dehydrogenase (MDH1), 3 PDC, 3 aldehyde dehydrogenase (ALDH), 5 $\mathrm{ADH}$, phosphoenolpyruvate carboxylase 4 (PPC4) and sucrose synthase (SUS2) were significantly upregulated in the roots.

\section{Biosynthesis of ethylene}

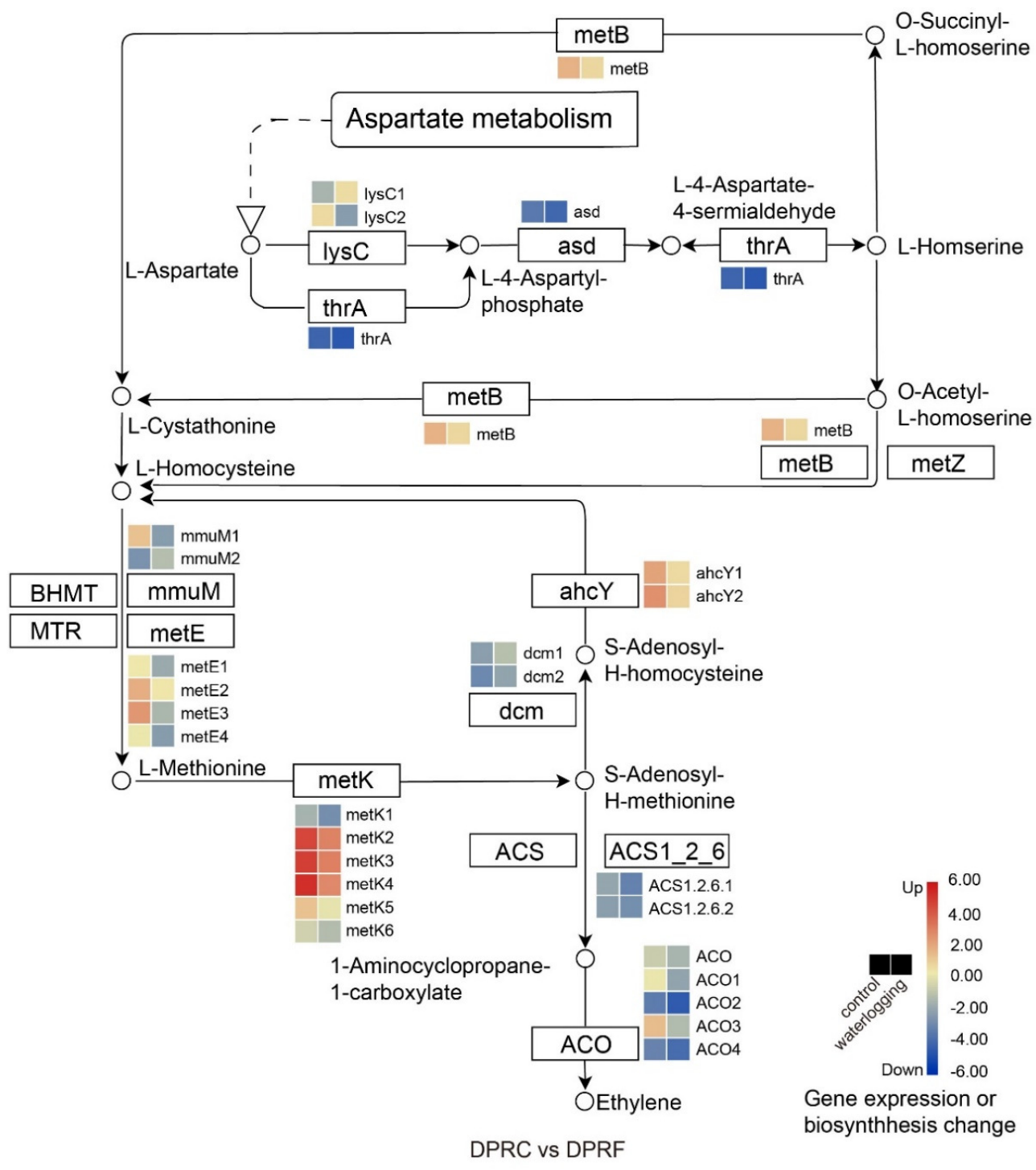

Figure 5. DEGs of Expression profile of biosynthesis of ethyleneth in P. deltoides 'DHY' roots under waterlogging stress

The sample names are showed at the bottom. The change in expression level is represented by the change in color, blue indicates a lower expression level and red indicates a higher expression level. All data shown are the average mean of three biological replicates $(n=3)$

Means with different letters at each treatment represented a significant difference at $p \leq 0.05$. 
(A)

(C)
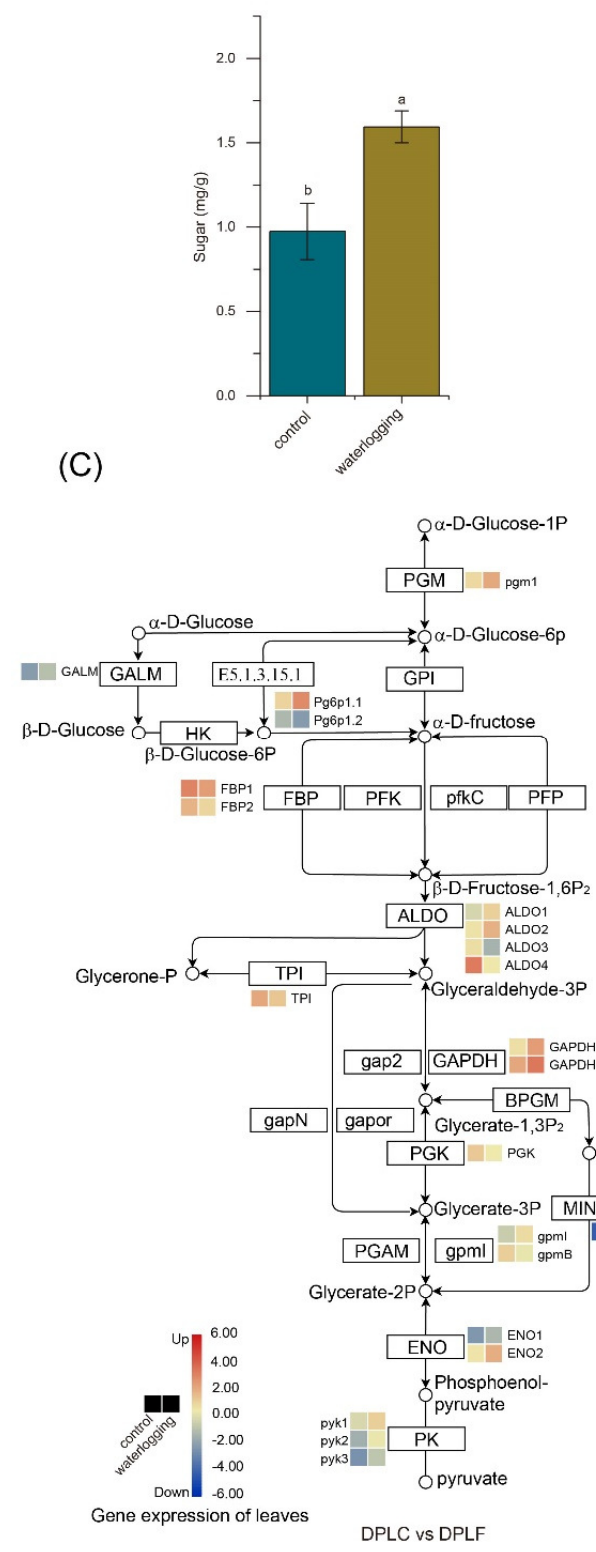

(B)

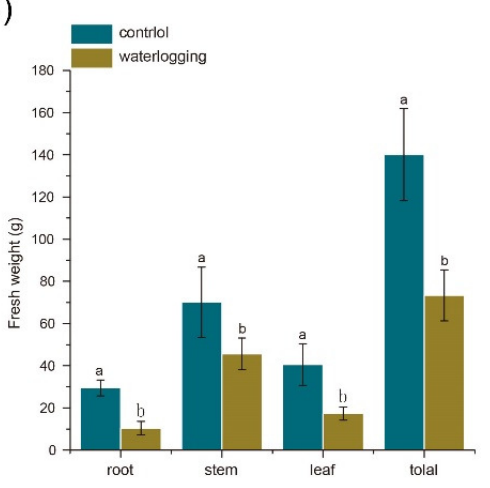

(D)

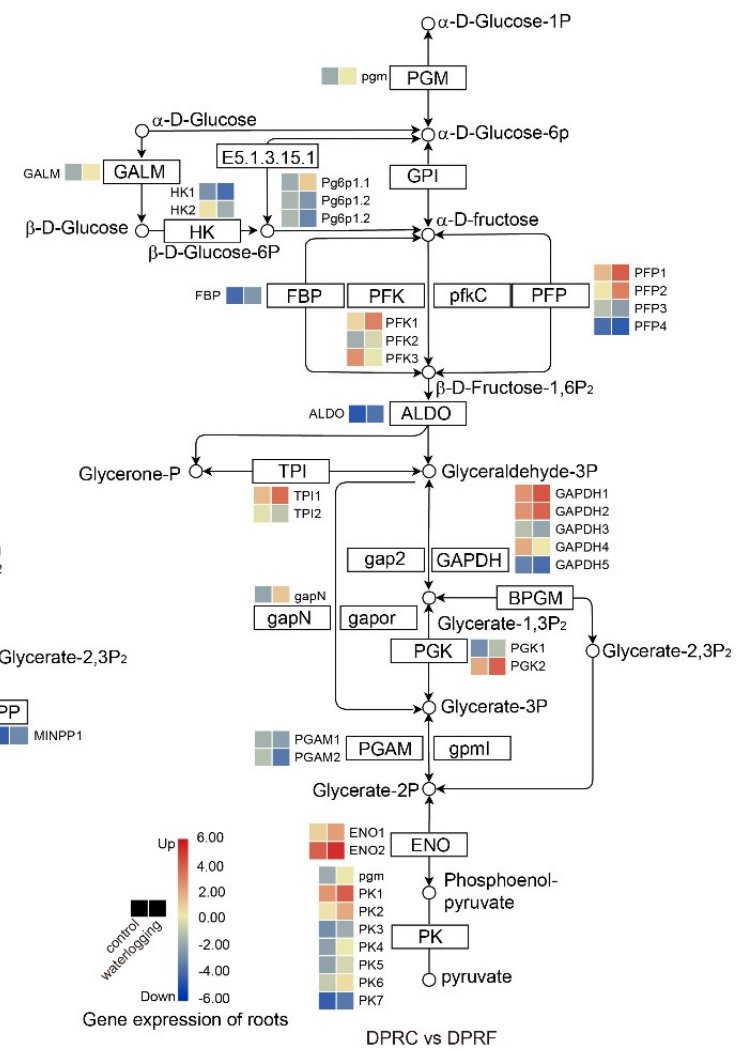

Figure 6. The content of sugar, biomass and expression profiles of DEGs related to sugar metabolism in waterlogging treatment of $P$. deltoides 'DHY'. (A) Comparison of sugar content in $P$. deltoides 'DHY' leaves of waterlogging treatments. (B) Comparison of biomass content in $P$. deltoides 'DHY' leaves of waterlogging treatments. (C) Expression profiles of DEGs related to sugar metabolism in $P$. deltoides 'DHY' leaf of waterlogging treatments. (D) Expression profiles of DEGs related to sugar metabolism in $P$. deltoides 'DHY'root of waterlogging treatments

The sample names are showed at the bottom. The change in expression level is represented by the change in color, blue indicates a lower expression level and red indicates a higher expression level. All data shown are the average mean of three biological replicates $(n=3)$. Means with different letters at each treatment represented a significant difference at $p \leq 0.05$. 
(A)

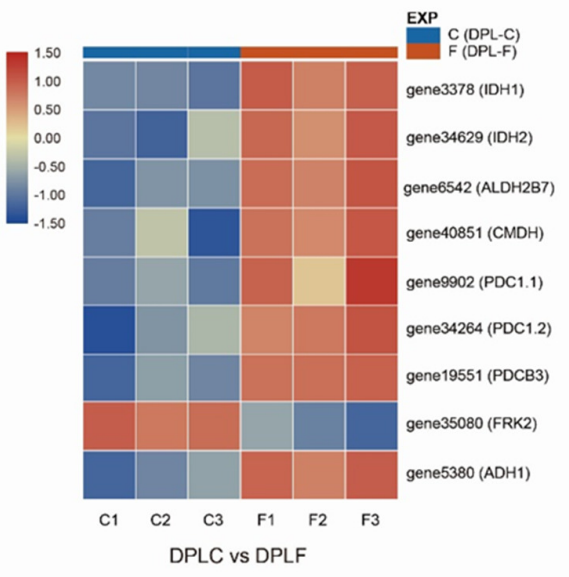

(B)

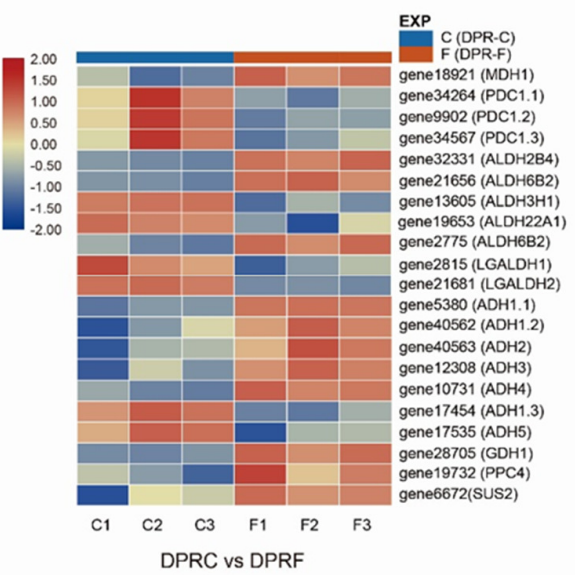

Figure 7. DEGs related to energy metabolism under waterlogging in P. deltoides 'DHY'. (A) Heatmap analysis of DEGs in leaves of $P$. deltoides 'DHY'related to energy metabolism. (B) Heatmap analysis of DEGs in roots of $P$. deltoides 'DHY' related to energy metabolism

The sample names are showed at the bottom. The change in expression level is represented by the change in color, blue indicates a lower expression level and red indicates a higher expression level. Means with different letters at each treatment represented a significant difference at $\mathrm{p} \leq 0.05$.

\section{DEGs associated with photosynthesis and chlorophyll fluorescence under waterlogging stress}

The net photosynthetic rate, stomatal conductance, intercellular $\mathrm{CO}_{2}$ concentration, and transpiration rate in the leaves of $P$. deltoides ' $\mathrm{DHY}$ ' were significantly lower than those in the control under waterlogging stress (Figure 8A). The maximum photosynthetic efficiency, the maximum fluorescence under light, the maximum fluorescence after dark adaptation, the apparent electron transport rate, photochemical quenching coefficient, and actual photochemical quantum yields also decreased significantly compared with the control (Figure 8B).

RNA-seq analysis showed that 50 DEGs related to photosynthesis and light response were involved in this pathway (Figure 8C and D), including genes such as photosystem I (PSI), photosystem II (PSII), lightharvesting complex I chlorophyll a/b binding protein 1 (LHCA), and light-harvesting complex II chlorophyll $\mathrm{a} / \mathrm{b}$ binding protein 3 (LHCB). The expression levels of most of the DEGs involved in photosynthesis and light response were significantly downregulated compared with the control.

Th DEGs associated with proline biosynthesis under waterlogging stress

The proline content in the leaves of $P$. deltoides 'DHY' was significantly higher than that of the control after $65 \mathrm{~d}$ of waterlogging (Figure 9A). A total of 24 and 51 DEGs related to proline biosynthesis were screened in the leaves and roots, respectively, from transcriptome data (Figure 9B). ALDO, TPI, GAPDH, PGK, PGAM, ENO, PK, aspartate aminotransferase (IDC), glutamine synthetase (GLNA) and aspartate aminotransferase (ASP5) were significantly upregulated in both leaves and roots, but PFK, ACO, glutamate synthase (NADH) (GLT), amino-acid N-acetyltransferase (ARGAB), aminoacylase (ACY), amino-acid Nacetyltransferase (ARGJ), arginase (ROCF) and delta-1-pyrroline-5-carboxylate synthetase (P5CS) were significantly upregulated only in roots under waterlogged conditions. 
(A)

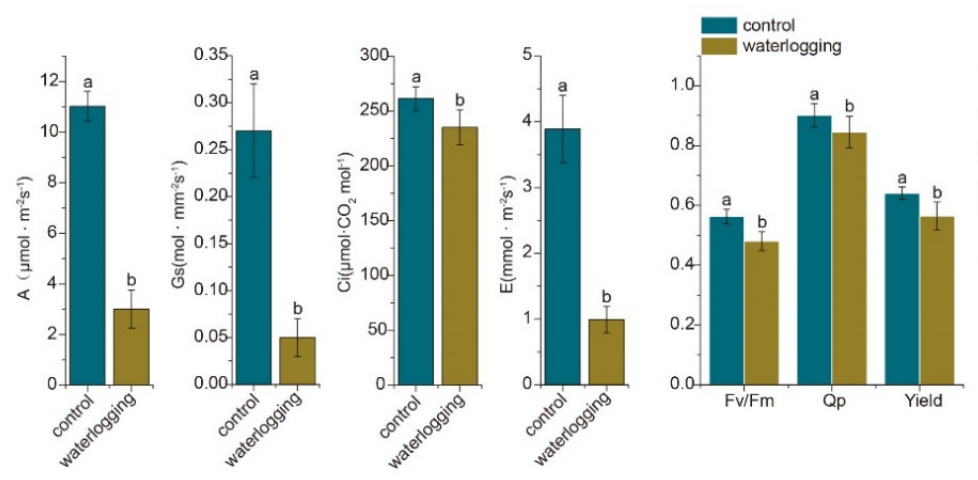

(B)

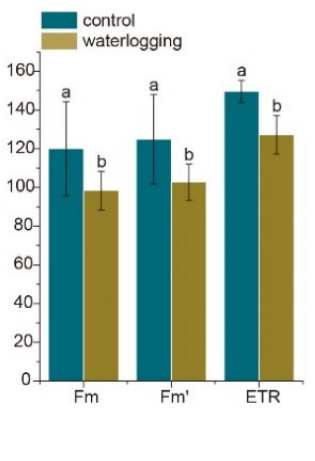

(C)

\section{Light reactions}

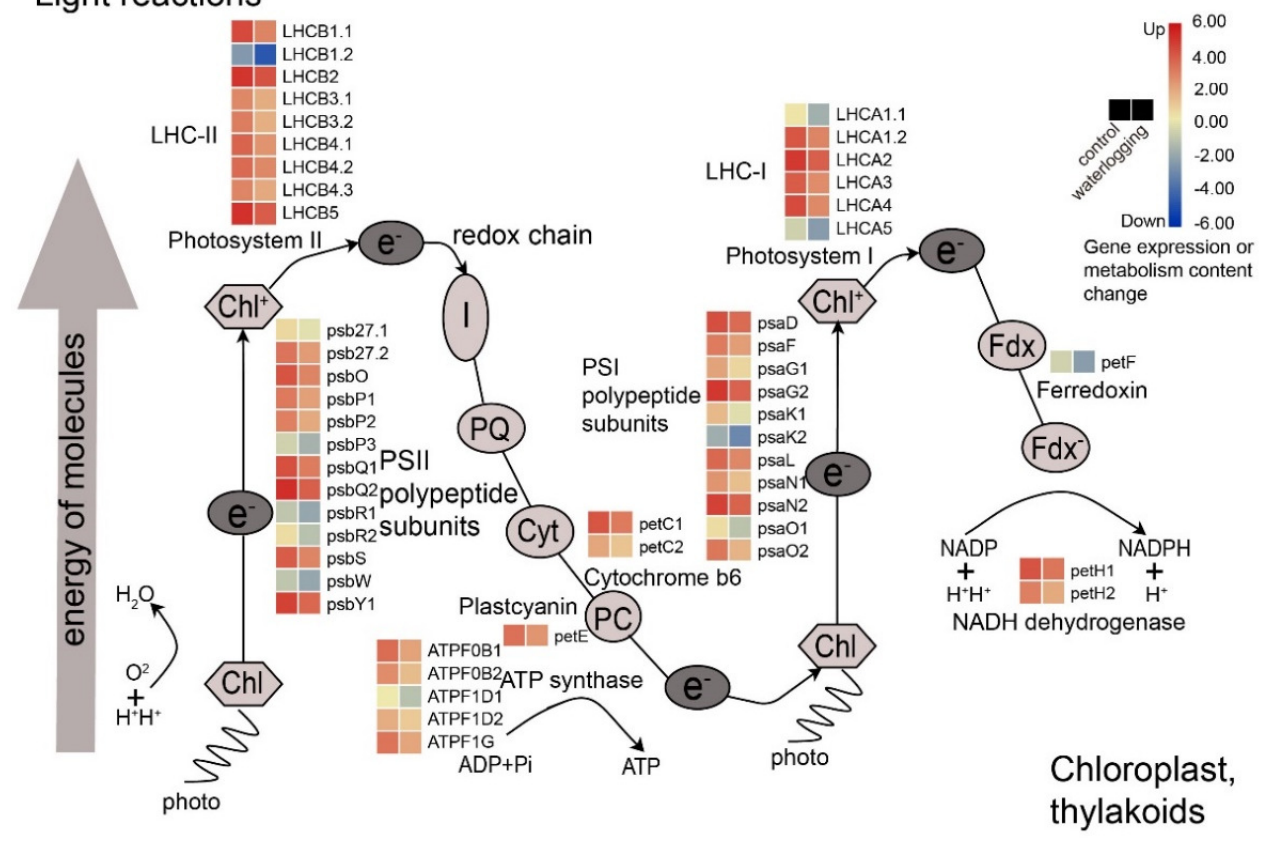

Figure 8. Comparison of physiological indexes during the waterlogging treatment of P. deltoides 'DHY' by two methods and expression profile analysis of DEGs. (A) Differential analysis of photosynthetic rate. (B) Differential analysis of chlorophyll fluorescence in leaves of P. deltoides 'DHY'. (C) Changes in the expression of photosynthesis-related genes in leaves of P. deltoides 'DHY'

The sample names are showed at the bottom. The change in expression level is represented by the change in color, blue indicates a lower expression level and red indicates a higher expression level. All data shown are the average mean of three biological replicates $(n=3)$. Means with different letters at each treatment represented a significant difference at $p \leq 0.05$. 
(A)

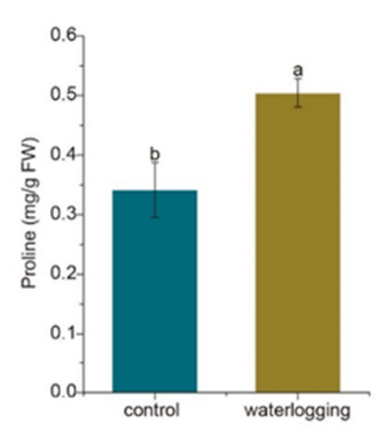

(B)

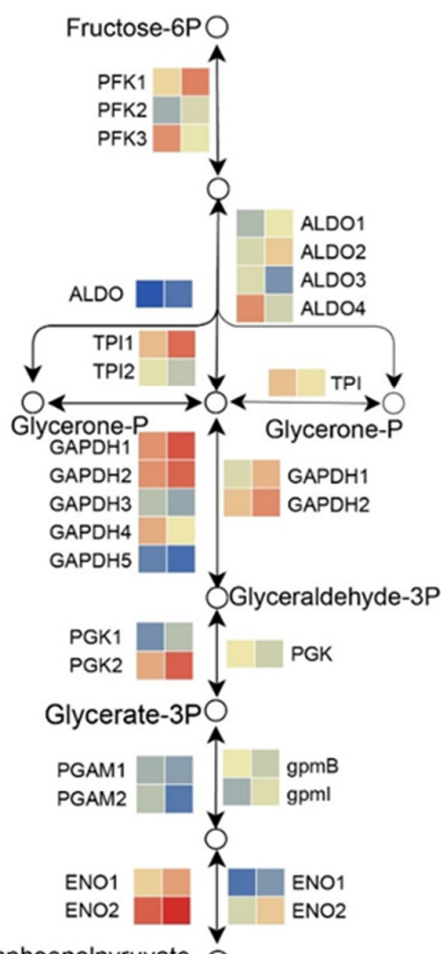

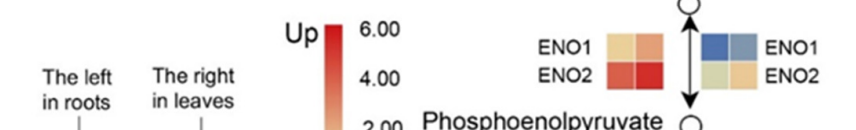

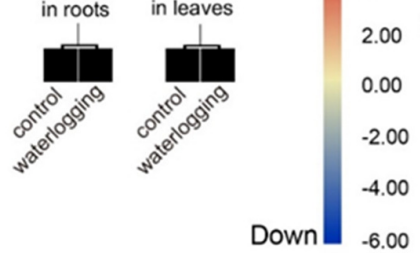

Gene expression or metabolism content change

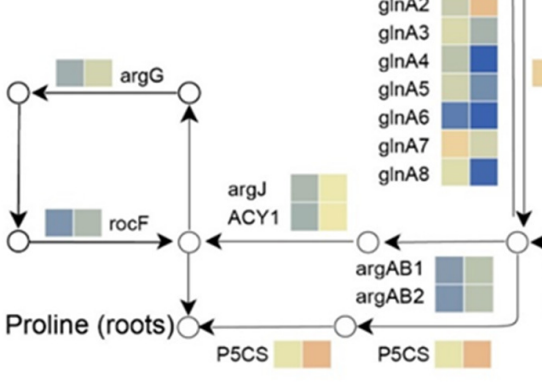

DPRC vs DPRF

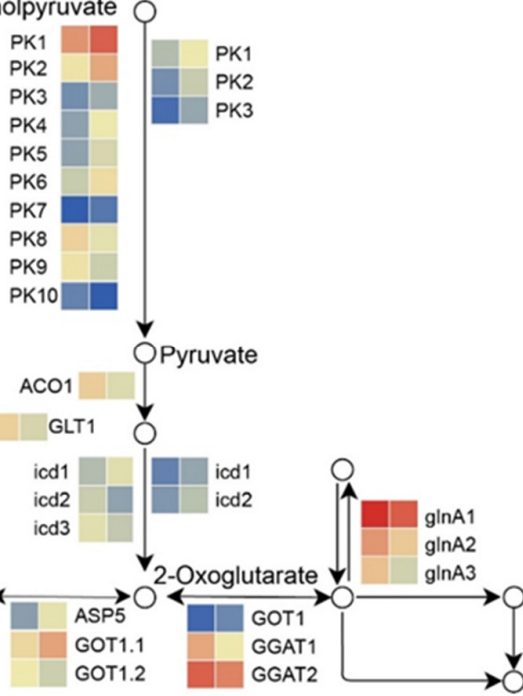

Proline(leaves)

DPLC vs DPLF

Figure 9. Comparison of proline content during the waterlogging treatment of $P$. deltoides 'DHY' and expression profile analysis of DEGs. (A) Comparison of pralines content in $P$. deltoides 'DHY' leaves of waterlogging treatments. (B) Expression profiles of DEGs related to proline biosynthesis in $P$. deltoides 'DHY' leaf and root of waterlogging treatments, expression profiles of the left in roots and the right in leaves. The sample names are showed at the bottom

The change in expression level is represented by the change in color, blue indicates a lower expression level and red indicates a higher expression level. All data shown are the average mean of three biological replicates $(n=3)$. Means with different letters at each treatment represented a significant difference at $p \leq 0.05$. 


\section{DEGs related to antioxidant and defense systems under waterlogging stress}

A total of 2 catalases (CAT), peroxidase (PER), respiratory burst oxidase homolog (ROBH), and 3 superoxide dismutases (SOD) were significantly downregulated and the gene expression levels of 3 glutathione s-transferases (GST) and 3 GST23s were significantly increased in the leaves of $P$. deltoides 'DHY' under waterlogging conditions (Figure 10A). Moreover, 3 GSTs, CAT1 and 3 SODs were significantly upregulated in the waterlogged roots of $P$. deltoides 'DHY'. However, peroxidase (POD) and $3 \mathrm{RBOH}$ s were significantly downregulated (Figure 10B). In addition, GSTU17 was found to be significantly downregulated in both leaves and roots under waterlogged conditions.

\section{DEGs related to TFs under waterlogging stress}

A total of 700 transcription factors were annotated in the leaves and roots of poplar under waterlogging stress and control and were classified into 62 families (Figure 11A), of which AP2/ERF-ERF family was the largest, including 75, followed by NAC, MYB, WRKY, C2H2, bHLH, and AUX/IAA. A total of 27 and 39 transcription factors of stress and defense response in the leaves and roots of $P$. deltoides ' $\mathrm{DHY}$ ' were observed through calorimetry analysis of DEG expression (Figure 11B and C). Significantly upregulated TFs included 2, 1, 2, and 8 members of the NAC, MYB, bHLH, and AP2/ERF family in flood-stressed leaves, whereas the downregulated transcription factor gene had one NACs. The significantly upregulated ones in the waterlogged roots included 5 members of WRKY family, 2 NAC022 of 2 NAC family, 1 MYB17 of MYB family, and 2 TFs of bHLH family; whereas the significantly downregulated ones included 1 WRKY22 of WRKY family and 8 TFs of AP2/ERF family. In addition, MYB86 of MYB family was found to be significantly downregulated in both leaves and roots under waterlogged conditions.
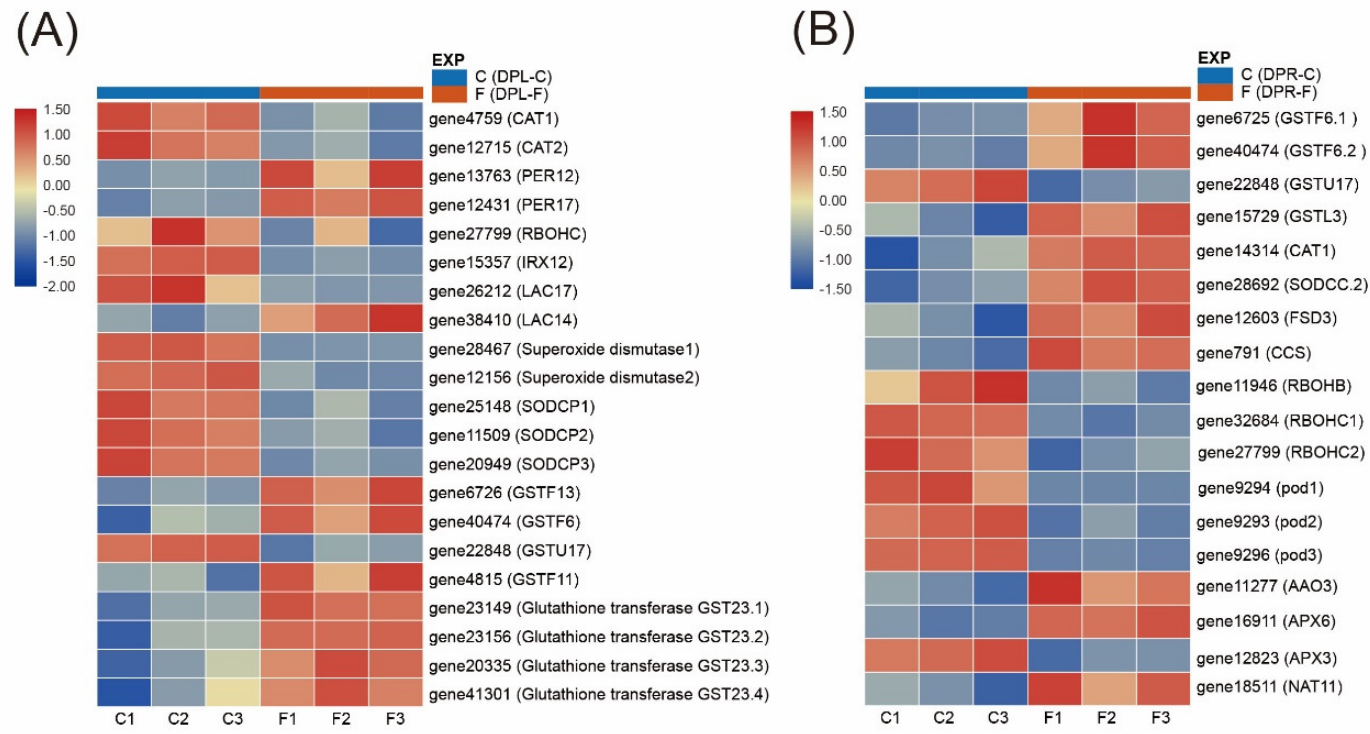

Figure 10. DEGs related to Antioxidant system under waterlogging in P. deltoides 'DHY'. (A) Heatmap analysis of DEGs in leaves of $P$. deltoides 'DHY' related to enzymatic scavenging system. (B) Heatmap analysis of DEGs in leaves of $P$. deltoides 'DHY' related to enzymatic scavenging system

The sample names are showed at the bottom. The change in expression level is represented by the change in color, blue indicates a lower expression level and red indicates a higher expression level. Means with different letters at each treatment represented a significant difference at $\mathrm{p} \leq 0.05$. 
(A)

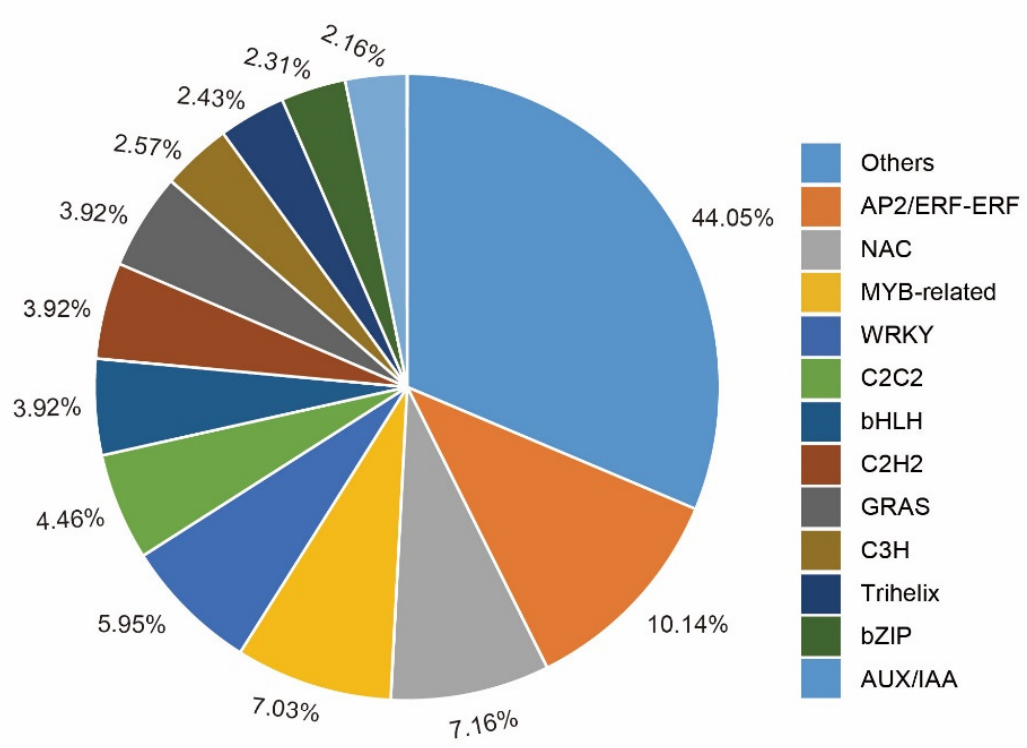

(B)

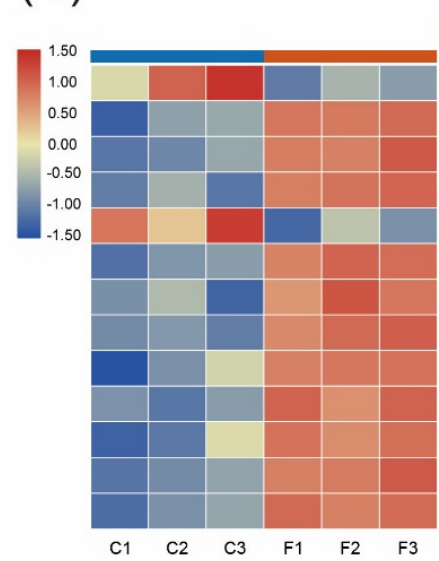

XP
F (DPL-C) gene26242 (NAC072) gene28665 (NAC047.1) gene37803 (NAC047.2) gene30620 (MYB7) gene27525 (MYB86) gene15127 (BHLH35.1) gene37223 (BHLH35.2) gene8629 (ERF2) gene5905 (RAP2.1.1) gene20863 (RAP2.3.1) gene22616 (RAP2.3.2) gene30869 (RAP2.3.3) gene5596 (RAP2.4)
(C)

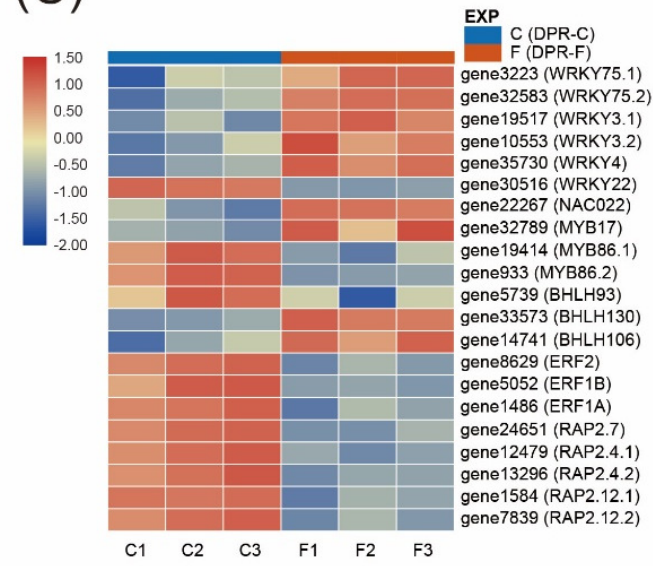

Fig. 11 Analysis of transcription factors (TFs) involved in P. deltoides 'DHY' under waterlogging. (A) Distribution of TF families in the transcriptome of $P$. deltoides ' DHY' under waterlogging. (B) Expression profiles of differentially expressed TFs involved in leaves of $P$. deltoides 'DHY' under waterlogging. (C) Expression profiles of differentially expressed TFs involved in roots of Populus trichocarpa under waterlogging

The sample names are showed at the bottom. The change in expression level is represented by the change in color, blue indicates a lower expression level and red indicates a higher expression level. Means with different letters at each treatment represented a significant difference at $\mathrm{p} \leq 0.05$.

\section{Discussion}

Initiation adventitious root primordia paly key role in the waterlogging tolerance of P. deltoides 'DHY'

$P$. deltoides 'DHY' under waterlogging treatment had fewer roots below the ground, and the leaves turned yellow but not abscission compared with the control form figure one. Simultaneously, the chlorophyll 
content showed a significant downward trend, indicating that $P$. deltoides ' $\mathrm{DHY}$ ' was inhibited to some extent under flood stress. Studies have shown that the decrease in chlorophyll content is thought to be caused by the acceleration of chlorophyll degradation or obstruction of chlorophyll synthesis (Zhu et al., 2018). In addition, a large number of adventitious roots were produced under waterlogging stress compared with the control. The formation of adventitious roots is an active adaptation mode of plants to waterlogging (Colmer et al., 2009), which can rapidly replace the primary roots suffocating and dying due to hypoxia. The porosity of the internal tissue of roots is greatly increased, and the energy of oxygen uptake and transportation is significantly improved, which is conducive to reducing the long-distance oxygen transportation (Rich et al., 2012 ; Xu et al., 2017). This feature has been reported in corn (Mano et al., 2009), cucumber (Xu et al., 2017), and soybean (Kim et al., 2015) under waterlogging stress.

Four important genes related to adventitious root formation were also excavated from the transcriptome data and significantly upregulated in the roots of $P$. deltoides 'DHY' under waterlogging stress. Studies have reported that the expression of ALF4 gene mutants in Arabidopsis thaliana thwarts the formation of lateral roots, which will also change the structure of the root system (DiDonato et al., 2014). SHR gene was identified in Arabidopsis to regulate the growth of adventitious roots. SHR is the regulator of adventitious roots in Arabidopsis thaliana, also necessary for the initiation and formation of lateral root primordia to maintain the infinite growth of lateral and anchored roots, and regulates the root-related development process (Lucas et al., 2011). Besides, the RID3 gene germinated in hypocotyls in Arabidopsis thaliana, which encoded an evolutionarily conserved methyltransferase-like protein localized in the nucleus and most prominently accumulated in the nucleoli (Ohbayashi et al., 2011). The AR primordium in Arabidopsis thaliana originates from the hypocotyl formation layer, forming lateral roots similar to the surrounding tissues of the native root (Verstraeten et al., 2013; Agulló-Antón et al., 2014), and LRP1.1 is highly expressed in P. deltoides 'DHY'. Therefore, results of this study indicate that waterlogged treatment induced the upregulated expression of some adventitious roots in $P$. deltoides 'DHY', which in turn produced adventitious roots to improve the unfavorable factors caused by hypoxia in waterlogged conditions and gradually restore normal metabolic pathways in plants.

Candidate genes related to stress response contribute to the waterlogging tolerance of $P$. deltoides 'DHY'

The response mechanisms of plants under waterlogging stress include changes in signal transduction, antioxidant system, and stress response (Ruperti et al., 2019). Therefore, screening stress response genes under waterlogging is crucial for understanding the molecular mechanism of poplar tolerance to waterlogging (Fukao et al., 2019). CML, CBL and CDPK in plants can monitor dynamic levels of calcium, and these proteins transmit signals and trigger responses from downstream genes (Valmonte et al., 2014). For example, the increased expression of NtCDPK 4 and OsCPK13 enhanced the tolerance to drought and high salt (Wan et al., 2007), and AtCPK6 overexpression in Arabidopsis thaliana increased the expression of stress-related genes and proline content (Xu et al., 2010). These results were verified in this study. The expression of LBD1 and CDPK genes in the leaves and roots of $P$. deltoides ' $\mathrm{DHY}$ ' were significantly upregulated under waterlogging stress in this study.

Three LBD genes were found to be upregulated in the leaves and roots of $P$. deltoides 'DHY' under waterlogging stress in this experiment. MtLBD1 can control the root structure of Medicago truncatula under salt stress (Ariel et al., 2010). Therefore, LBD gene was speculated to play a positive role in regulating waterlogging stress. A total of 3 Aquaporin TIPs (TIP) and aquaporin PIP (PIP)in leaves, and 4 TIPs in the roots of $P$. deltoides 'DHY' were downregulated under the waterlogging stress in this study. The plasma membrane of the aquaporin gene plays an important role in maintaining the water balance of plants under the condition of excessive water content of protein gene and inner protein of vacuole membrane to reduce the damage of osmotic stress between cells caused by excessive water content (Galmés et al., 2007). Therefore, the physiological interference caused by waterlogging to plants could be reduced by downregulating the expression 
of these aquaporin genes in $P$. deltoides 'DHY' under the stress of waterlogging is reasonable (Kadam et al., 2017).

Function of Hormonal regulation of AR emergence in the waterlogging tolerance of P. deltoides 'DHY'

The formation of adventitious roots and plant ethylene-induced adventitious roots under waterlogging stress depended on the directional transport of polar auxins (Vidoz et al., 2010). RNA-seq results showed that ARF17 and GH3 genes were upregulated in the leaves and roots of $P$. deltoides 'DHY' under waterlogging conditions. ARF17 positively regulated GH3 genes, and members of the $\mathrm{GH} 3$ protein family participated in the homeostasis of auxin (Kramer et al., 2015). In addition, the PIN protein gene upregulated in the roots of P. deltoides 'DHY' is involved in the transport of intracellular auxin (Adamowski et al., 2015). Hence, auxin may play an important role in regulating the growth of adventitious roots. This study found that NCED1, a key gene involved in ABA biosynthesis, was upregulated in the leaves of P. deltoides 'DHY', but NCED1 and NCED3 were downregulated in roots, and ABA receptor-related genes were downregulated in the leaves and roots under waterlogged conditions. This result is consistent with the decrease in ABA content and expression of related genes in hypocotyls of cucumber after $48 \mathrm{~h}$ of waterlogging and can promote the synthesis of adventitious roots (Dawood et al., 2016; Xu et al., 2017).

Studies have shown that ethylene signals can be detected within a few hours after waterlogging stress, play a key role in the plants' response to waterlogging, and activate downstream gene expression to promote the growth of adventitious roots (Phukan et al., 2016). However, the long-term increase of ethylene content can do harm to plant root growth (De and Hanecakova, 2008). Accumulation of ethylene in plant tissues increased the rate of active oxygen generation, leading to the destruction of macromolecules and ultimately cell death (Ahmed et al., 2006). RNA-seq results showed that 28 DEGs involved in the ethylene biosynthetic pathway were screened out from waterlogged and control $P$. deltoides 'DHY', and the expression levels of most DGEs were significantly downregulated and low-expressed. This finding means that the roots of $P$. deltoides 'DHY' can reduce the release of ethylene and increase the plants' tolerance to waterlogging stress by downregulating the expression of the above genes in waterlogged conditions.

Role of sugar in the waterlogging tolerance of $P$. deltoides ' $D H Y$ '

Many studies have found that the content of soluble sugar in plants is significantly increased under waterlogging conditions, which is an adaptation and protection mechanism for adversity and provides energy under hypoxic conditions (Peng et al., 2018). This study also detected that the soluble sugar content in $P$. deltoides ' $\mathrm{DHY}$ ' under waterlogged conditions was significantly higher than that of the control. RNA-seq analysis further excavated 22 and 38 DEGs involved in sugar metabolism pathways. IDH, CMDH, and PDC genes in the leaves were upregulated, which promoted the normal function of the tricarboxylic acid cycle metabolic pathway (Rocha et al., 2009). One MDH1 was also upregulated in the roots, indicating that the energy metabolism pathways in the leaves and roots of $P$. deltoides 'DHY' may be relieved by hypoxia from adventitious roots, allowing plants to perform normal mitochondrial respiration under aerobic conditions. In addition, the PDC in the root downregulated the expression, which inhibited the tricarboxylic acid cycle (Rocha et al., 2009). A significant upregulated SUS2 gene was also found in the roots of $P$. deltoides 'DHY' under waterlogging treatment. The protease has been proved to catalyze the transformation of sucrose into glucose, which led to the inhibition of mitochondrial respiration (Zabalza et al., 2009), thereby increasing the tolerance of red poplar to waterlogging. $\mathrm{ADH}$ was upregulated in the roots and leaves of $P$. deltoides ' $\mathrm{DHY}$ ' under waterlogging stress, which promoted the ethanol fermentation pathway and accelerated the degradation of ethanol (Arora et al., 2017). This result may also be one of the reasons why P. deltoides 'DHY' resisted waterlogging stress by activating ethanol metabolism. 
Candidate genes associated with photosynthesis and chlorophyll fluorescence participate in the waterlogging tolerance of $P$. deltoides ' $D H Y$ '

The gas photosynthetic parameters and photosynthetic fluorescence parameters of $P$. deltoides 'DHY' leaves were significantly decreased under waterlogging conditions compared with the control, and similar findings were also found in P. deltoides and Jerusalem artichoke (Miao et al., 2017; Yan et al., 2018). Moreover, most genes related to photosynthesis, including PSII, PSI, cytochrome b6/f complex, ATP synthase, photosynthetic electron transport chain, and photosynthetic antenna protein, were also significantly reduced in the leaves of $P$. deltoides 'DHY'. A total of 13 transcripts were significantly differentially expressed in PSII, but only 11 transcripts were differentially expressed in PSI, indicating that PSII is more sensitive than PSI under waterlogging stress. This result is consistent with previous reports that PSI is generally more stable than PSII under stress (Doupis et al., 2016; Zhu et al., 2018). In summary, transcriptome comparison and physiological test results showed that long-term waterlogging stress of $P$. deltoides ' $\mathrm{DHY}$ ' was closely related to the primary photosynthetic metabolic process, and the decrease in photosynthetic activity was also related to the blocked chlorophyll synthesis.

Candidate genes involved in antioxidant and defense systems requirements for the waterlogging tolerance of $P$. deltoides ' $D H Y$ '

Plants have evolved a series of enzymatic ROS clearance mechanisms to maintain intracellular ROS balance. The activities of APX and GR under waterlogging conditions in the leaves of $P$. deltoides 'DHY' were significantly increased compared with the control, indicating that these two enzymes participate in the removal of excessive ROS in the plant, thereby reducing the damage to the plants. $\mathrm{ROBH}$ is a rate-limiting enzyme produced by reactive oxygen species. $\mathrm{ROBH}$ forces mitochondrial respiratory pathway to reach the saturation of redox chain under hypoxia stress, accumulating NAD $(\mathrm{P}) \mathrm{H}$ and producing ROS (Yamauchi et al., 2014; He et al., 2015), which is the main source of ROS outbreak under waterlogging stress (Shabala et al., 2014). ROBH expression levels in the leaves and roots of $P$. deltoides 'DHY' were significantly downregulated under waterlogging stress. Hence, the rate of ROS production in the leaves and roots of $P$. deltoides 'DHY' was declining, and the oxidative damage suffered gradually. In addition, the expression of GSTF and GST in the leaves and APX and SOD antioxidant enzyme genes in roots were upregulated under waterlogging conditions, indicating that these two genes are involved in the important role of tolerance to waterlogging (Waszczak et al., 2018).

Activation of proline biosynthesis in the waterlogging tolerance of P. deltoides 'DHY'

Proline has excellent ROS scavenging ability, and abiotic stress leads to an increase in plant proline content (Alia and Sardhi, 1991). The proline content in P. deltoides 'DHY' leaves also showed a significant upward trend under the waterlogging stress, which is consist with waterlogging resistance in maize (Kravi et al., 2013). Results of KEGG analysis showed that five genes (ALDO, GAPDH, ENO, PK, GOT) related to proline synthesis pathway were significantly upregulated in the leaves and roots of $P$. deltoides 'DHY'. Simultaneously, this finding is consistent with the results of DEGs in the leaves and roots of our transcriptome. The above results indicate that $P$. deltoides 'DHY' can tolerate waterlogging stress by inducing the proline synthesis pathway gene expression under waterlogging stress to promote proline synthesis.

\section{Candidate TFs associated with the waterlogging tolerance of P. deltoides ' $D H Y$ '}

Transcription factors are key regulators of responses to various biotic or abiotic stresses (Singh et al., 2002). Transcription factors known to cope with waterlogging stress include bZIP (Yang et al., 2009), NAC (Wang et al., 2019), WRKY (Jiang et al., 2009), MYB (Li et al., 2019), AP2/ERF (Sasidharan et al., 2015) and bHLH family (Jing et al., 2017). AP2/ERF family members, including RAP2.1.1, 3 RAP2.3, RAP2.4, and 3 DREB transcription factors were significantly upregulated in response to hypoxia in $P$. deltoides ' $D H Y$ ' leaves, but 2 RAP 2.12, RAP 2.4, and DREB2A in roots were significantly downregulated. The lack of oxygen in the 
submerged roots can be alleviated due to the germination of adventitious roots. However, the oxygen content in the leaves was low, which promoted hypoxia in response to transcription factors. This result is consistent with the stability of the transcription factor RAP2.12 and results of dynamic regulation of nuclear localization by oxygen concentration (Monika et al., 2015). A total of 2 NAC, 2 WRKY, and bHLH transcription factor genes were upregulated in the leaves and roots under waterlogging stress. These transcription factor genes were inferred to play an important role in the waterlogging tolerance of $P$. deltoides 'DHY', and their functions in waterlogging tolerance need further verification.

\section{Conclusions}

This study provided a new understanding of the mechanism of waterlogging tolerance and the formation of adventitious roots of poplar under waterlogging conditions through the comparative analysis of RNA-seq and physiological indexes. Waterlogging can make a series of changes in plant morphology, physiology, photosynthesis, antioxidant enzyme system, energy metabolism, and the germination of the adventitious roots to promote the adaptation and long-term growth of $P$. deltoides ' $\mathrm{DHY}$ '. The mechanism of tolerance to waterlogging was elucidated from morphology and physiology aspects to molecule to provide an important basis for molecular breeding of poplar.

\section{Authors' Contributions}

G.L., M.H., Z.L., F.X and Z.Z conceived and designed the experiment. G.L., J.Y., W.Z. and F.X. analyzed the data. Y.L., participated validation and investigation. G.L. and F.X. wrote the paper. All authors prepared, read, and approved the final manuscript.

\section{Acknowledgements}

This work was supported by the by the Demonstration Project of Forestry Science and Technology funded by the Central Government of China (The Plan of Forestry Department of Hubei Province, Grant No. [2015]HBTK07), Hubei Provincial Key Technology Support Program of Forestry (Grant No. Lykjizc201209) and the Open Project Program of Engineering Research Center of Ecology and Agricultural Use of Wetland, Ministry of Education (No. KF201907).

\section{Conflict of Interests}

The authors declare that there are no conflicts of interest related to this article.

\section{References}

Adamowski M, Friml J (2015). PIN-dependent auxin transport: action, regulation, and evolution. The Plant Cell 27(1):20-32. https://doi.org/10.1105/tpc.114.134874

Agulló-Antón MÁ, Ferrández-Ayela A, Fernández-García N, Nicolás C, Albacete A, Pérez-Alfocea F, ... Acosta M (2014). Early steps of adventitious rooting: morphology, hormonal profiling and carbohydrate turnover in carnation stem cuttings. Physiologia Plantarum 150(3):446-462. https://doi.org/10.1111/ppl.12114 
Ahmed S, Nawata E, Sakuratani T (2006). Changes of endogenous ABA and ACC, and their correlations to photosynthesis and water relations in mungbean (Vigna radiata (L.) Wilczak cv. KPS1) during waterlogging. Environmental and Experimental Botany 57(3):278-284. https://doi.org/10.1016/j.envexpbot.2005.06.006

Alia P, Sardhi P (1991). Proline accumulation under heavy metal stress. Journal of Plant Physiology 138(5):554-558.

Arbona V, Manzi M, Zandalinas SI, Vives-Peris V, Pérez-Clemente RM, Gómez-Cadenas A (2017). Physiological, metabolic, and molecular responses of plants to abiotic stress. In: Stress Signaling in Plants: Genomics and Proteomics Perspective Volume 2 (Springer, Cham) pp 1-35. https://doi.org/10.1007/978-3-319-42183-4_1

Ariel FD, Diet A, Crespi M, Chan RL (2010). The LOB-like transcription factor MtLBD1 controls Medicago truncatula root architecture under salt stress. Plant Signaling \& Behavior 5(12):1666-1668. https://doi.org/10.4161/psb.5.12.14020

Arora K, Panda KK, Mittal S, Mallikarjuna MG, Rao AR, Dash PK, Thirunavukkarasu N (2017). RNAseq revealed the important gene pathways controlling adaptive mechanisms under waterlogged stress in maize. Scientific Reporters 7(1):1-12. https://doi.org/10.1038/s41598-017-10561-1

Bailey-Serres J, Voesenek L (2008). Flooding stress: acclimations and genetic diversity. Annual Review of Plant Biology 59:313-339. https://doi.org/10.1146/annurev.arplant.59.032607.092752

Colmer TD (2003). Long-distance transport of gases in plants: a perspective on internal aeration and radial oxygen loss from roots. Plant, Cell \& Environment 26(1):17-36. https://doi.org/10.1046/j.1365-3040.2003.00846.x

Colmer TD, Voesenek LACJ (2009). Flooding tolerance: suites of plant traits in variable environments. Functional Plant Biology 36(8):665-681. https://doi.org/10.1071/fp09144

Coudert Y, Périn C, Courtois B, Khong NG, Gantet P (2010). Genetic control of root development in rice, the model cereal. Trends in Plant Science 15(4):219-226. https://doi.org/10.1016/j.tplants.2010.01.008

Dawood T, Yang X, Visser EJ, TeBeek TA, Kensche PR, Cristescu SM, Rieu I (2016). A co-opted hormonal cascade activates dormant adventitious root primordia upon waterlogging in Solanum dulcamara. Plant Physiology 170(4):2351-2364. https://doi.org/10.1104/pp.15.00773

De-Klerk GJ, Hanecakova J (2008). Ethylene and rooting of mung bean cuttings. The role of auxin induced ethylene synthesis and phase-dependent effects. Plant Growth Regulation 56(2):203. https://doi.org/10.1007/s10725008-9301-8

DiDonato RJ, Arbuckle E, Buker S, Sheets J, Tobar J, Totong R, Celenza JL (2004). Arabidopsis ALF4 encodes a nuclearlocalized protein required for lateral root formation. The Plant Journal 37(3):340-353. https://doi.org/10.1046/j.1365-313X.2003.01964.X

Doupis G, Kavroulakis N, Psarras G, Papadakis IE (2016). Growth, photosynthetic performance and antioxidative response of 'Hass' and 'Fuerte' avocado (Persea americana Mill.) plants grown under high soil moisture. Photosynthetica 55(4):655-663. https://doi.org/10.1007/s11099-016-0679-7

Du K, Xu L, Wu H, Tu B, Zheng B (2012). Ecophysiological and morphological adaption to soil flooding of two poplar clones differing in flood-tolerance Flora-Morphology, Distribution, Functional Ecology of Plants 207(2):96-106. https://doi.org/10.1016/j.flora.2011.11.002

Fukao T, Barrera-Figueroa BE, Juntawong P, Peña-Castro JM (2019). Submergence and waterlogging stress in plants: a review highlighting research opportunities and understudied aspects. Frontiers in Plant Science 10:340. https://doi.org/10.3389/fpls.2019.00340

Galmés J, Pou A, Alsina MM, Tomas M, Medrano H, Flexas J (2007). Aquaporin expression in response to different water stress intensities and recovery in Richter-110 (Vitis sp.): relationship with ecophysiological status. Planta 226(3):671-681. https://doi.org/10.2307/23389706

Grabherr MG, Haas BJ, Yassour M, Levin JZ, Thompson DA, Amit I (2011). Full length transcriptome assembly from RNA-Seq data without a reference genome. Nature Biotechnology 29(7):644. https://doi.org/10.1038/nbt.1883

He LZ, Li B, Lu XM, Yuan LY, Yang YJ, Yuan YH, Du J, Guo SR (2015). The effect of exogenous calcium on mitochondria, respiratory metabolism enzymes and ion transport in cucumber roots under hypoxia. Scientific Reports 5:11391. https://doi.org/10.1038/srep11391

Irfan M, Hayat S, Hayat Q, Afroz S, Ahmad A (2010). Physiological and biochemical changes in plants under waterlogging. Protoplasma 241:3-17. https://doi.org/ 10.1007/s00709-009-0098-8

Jackson MB, Ishizawa K, Ito O (2009). Evolution and mechanisms of plant tolerance to flooding stress. Annals of Botany 103:137-142. https://doi.org/10.1093/aob/mcn242 
Jiang Y, Deyholos MK (2009). Functional characterization of Arabidopsis NaCl-inducible WRKY25 and WRKY33 transcription factors in abiotic stresses. Plant Molecular Biology 69(1-2):91-105. https://doi.org/10.1007/s11103-008-9408-3

Jing Z, Li, Z (2018). Genome-wide identification of wrky transcription factors in kiwifruit (Actinidia spp.) and analysis of wrky expression in responses to biotic and abiotic stresses. Genes \& Genomics 40(4): 429-446. https://doi.org/.10.1007/s13258-017-0645-1

Kadam S, Abril A, Dhanapal AP, Koester RP, Vermerris W, Jose S, Fritschi FB (2017). Characterization and regulation of aquaporin genes of sorghum Sorghum bicolor (L.) Moench in response to waterlogging stress. Frontiers in Plant Science 8:862. https://doi.org/10.3389/fpls.2017.00862

Kim KN (2013). Stress responses mediated by the CBL calcium sensors in plants. Plant Biotechnology Reports 7(1):1-8. https://doi.org/0.1007/s11816-012-0228-1

Kim YH, Hwang SJ, Waqas M, Khan AL, Lee JH, Lee JD, Lee IJ (2015). Comparative analysis of endogenous hormones level in two soybeans (Glycine max L.) lines differing in waterlogging tolerance. Frontiers in Plant Science 6:714. https://doi.org/10.3389/fpls.2015.00714

Kramer EM, Ackelsberg EM (2015). Auxin metabolism rates and implications for plant development. Frontiers in Plant Science 6:150. https://doi.org/10.3389/fpls.2015.00150

Kravi N, Markovi K, Anelkovi V, Ukalovi HT, Babi V, Vuleti, M (2013). Growth, proline accumulation and peroxidase activity in maize seedlings under osmotic stress. Acta Physiologiae Plantarum 35(1):233-239. https://doi.org/10.1016/S0176-1617(11)80240-3

Licausi F, Kosmacz M, Weits DA, Giuntoli B, Giorgi FM, Voesenek LACJ, ... Perata P (2011). Oxygen sensing in plants is mediated by an N-end rule pathway for protein destabilization. Nature 479(7373):419-422. https://doi.org/10.1038/nature10536

Li J, Han G, Sun C, Sui N (2019). Research advances of MYB transcription factors in plant stress resistance and breeding. Plant Signaling \& Behavior 14(8):1613131. https://doi.org/10.1080/15592324.2019.1613131

Lucas M, Swarup R, Paponov IA, Swarup K, Casimiro I, Lake D, ... Wang J (2011). Short-Root regulates primary, lateral, and adventitious root development in Arabidopsis. Plant Physiology 155(1):384-398. https://doi.org/10.2307/41434010

Mano Y, Omori F, Loaisiga CH, Bird R (2009). QTL mapping of above-ground adventitious roots during waterlogging in maize teosinte Zea nicaraguensis backcross population. Plant Root 3:3-9. https://doi.org/10.3117/plantroot.3.3

Miao LF, Yang F, Han CY, Pu YJ, Ding Y, Zhang LJ (2017). Sex-specific responses to winter flooding, spring waterlogging and post-flooding recovery in Populus deltoides. Science. Reporters 7(1):2534. https://doi.org/10.1038/s41598017-02765-2

Monika K, Sandro P, Markus S, Friedrich K, Licausi F, Van-Dongen JT (2015). The stability and nuclear localization of the transcription factor RAP2. 12 are dynamically regulated by oxygen concentration. Plant, Cell \& Environment 38:1094-1103. https://doi.org/10.1111/pce.12493

Moustakas M, Sperdouli I, Kouna T, Antonopoulou CI, Therios I (2011). Exogenous proline induces soluble sugar accumulation and alleviates drought stress effects on photosystem ii functioning of Arabidopsis thaliana leaves. Plant Growth Regulation 65(2):315-325. https://doi.org/10.1007/s10725-011-9604-Z

Nascimento KJT, Debona D, Rezende D, DaMatta FM, Rodrigues FÁ (2018). Changes in leaf gas exchange and chlorophyll a fluorescence on soybean plants supplied with silicon and infected by Cercospora sojina. Journal of Phytopathology 166 (11-12):747-760. https://doi.org/10.1111/jph.12757

Ohbayashi I, Konishi M, Ebine K, Sugiyama M (2011). Genetic identification of Arabidopsis RID2 as an essential factor involved in pre-rRNA processing. The Plant Journal 67(1):49-60. https://doi.org/10.1111/j.1365$313 x .2011 .04574 . x$

Peng Y, Zhou Z, Zhang Z, Yu X, Zhang X, Du K (2018). Molecular and physiological responses in roots of two full-sib poplars uncover mechanisms that contribute to differences in partial submergence tolerance. Scientific Reports 8(1):12829. https://doi.org/10.1038/s41598-018-30821-y

Phukan UJ, Mishra S, Shukla RK (2016). Waterlogging and submergence stress: affect and acclimation. Critical Reviews in Biotechnology 36(5):956-966. https://doi.org/10.3109/07388551.2015.1064856

Rich SM, Ludwig M, Colmer TD (2012). Aquatic adventitious root development in partially and completely submerged wetland plants Cotula coronopifolia and Meionectes brownie. Annals of Botany 110(2):405-414. https://doi.org/10.1093/aob/mcs051 
Rocha M, Licausi F, Araújo WL, Nunes-Nesi A, Sodek L, Fernie AR, Van-Dongen JT (2010). Glycolysis and the tricarboxylic acid cycle are linked by alanine aminotransferase during hypoxia induced by waterlogging of Lotus japonicus. Plant Physiology 152(3):1501-1513. https://doi.org/10.1104/pp.109.150045

Ruperti B, Botton A, Populin F, Eccher G, Brilli M, Quaggiotti S, Guarracino P, Meggio F (2019). Flooding responses on grapevine: a physiological, transcriptional and metabolic perspective. Frontiers in Plant Science 10:339. https://doi.org/10.3389/fpls.2019.00339

Sairam RK, Dharmar K, Chinnusamy V, Lekshmy S, Joshi R, Bhattacharya P (2011). NADPH oxidase as the source of ROS produced under waterlogging in roots of mung bean. Biologia Plantarum 55(4):746. https://doi.org/10.1007/s10535-011-0179-3

Sasidharan R, Voesenek LA (2015). Ethylene-mediated acclimations to flooding stress. Plant Physiology 169(1):3-12. https://doi.org/10.1104/pp.15.00387

Shabala S, Shabala L, Barcelo J, Poschenrieder C (2014). Membrane transporters mediating root signaling and adaptive responses to oxygen deprivation and soil flooding. Plant, Cell \& Environment 37(10):2216-2233. https://doi.org/10.1111/pce.12339

Singh K, Foley RC, Onate-Sanchez L (2002). Transcription factors in plant defense and stress responses. Current Opinion in Plant Biology 5(5):430-436. https://doi.org/10.1016/S1369-5266(02)00289-3

Striker GG, Colmer TD (2017). Flooding tolerance of forage legumes. Journal of Experimental Botany 68(8):1851-1872. https://doi.org/10.1093/jxb/erw239

Tewari S, Arora N, Miransari M (2016). Plant growth promoting rhizobacteria to alleviate soybean growth under abiotic and biotic stresses. In: Abiotic and Biotic Stresses in Soybean Production. Academic Press pp 131-155. https://doi.org/10.1016/B978-0-12-801536-0.00006-2

Tuskan GA, Difazio S, Jansson S, Bohlmann J, Grigoriev I, Hellsten U, ... Schein J (2006). The genome of black cottonwood, Populus trichocarpa. Science 313(5793):1596-1604. https://doi.org/10.1126/science.1128691.

Valmonte GR, Arthur K, Higgins CM, MacDiarmid RM (2014) Calcium-dependent protein kinases in plants: evolution, expression and function. Plant and Cell Physiology 55(3):551-569. https://doi.org/10.1093/pcp/pct200

Verstraeten I, Beeckman T, Geelen D (2013). Adventitious root induction in Arabidopsis thaliana as a model for in vitro root organogenesis. In: Plant Organogenesis. Humana Press Totowa NJ pp 159-175. https://doi.org/10.1007/978-1-62703-221-6_10

Vidoz ML, Loreti E, Mensuali A, Alpi A, Perata P (2010). Hormonal interplay during adventitious root formation in flooded tomato plants. The Plant Journal 63(4):551-562. https://doi.org/10.1111/j.1365-313X.2010.04262.X

Voesenek LACJ, Bailey-Serres J (2013). Waterlogging tolerance: $\mathrm{O}_{2}$ sensing and survival strategies. Current Opinion in Plant Biology 16:647-653. https://doi.org/10.1016/j.pbi.2013.06.008

Wan B, Lin Y, Mou T (2007). Expression of rice $\mathrm{Ca}^{2+}$-dependent protein kinases (CDPKs) genes under different environmental stresses. FEBS Letters 581(6):1179-1189. https://doi.org/10.1016/j.febslet.2007.02.030

Wang Z, Hua J, Yin Y, Gu C, Yu C, Shi Q, Yu F, et al (2019). An integrated transcriptome and proteome analysis reveal putative regulators of adventitious root formation in Taxodium 'Zhongshanshan'. International Journal of Molecular Sciences 20(5):12-25. https://doi.org/10.3390/ijms20051225

Waszczak C, Carmody M, Kangasjärvi J (2018). Reactive oxygen species in plant signaling. Annual Review of Plant Biology 69:209-236. https://doi.org/10.1146/annurev-arplant-042817-040322

Wellburn, Alan R (1994). The spectral determination of chlorophylls a and b, as well as total carotenoids, using various solvents with spectrophotometers of different resolution. Journal of Plant Physiology 144(3):307-313. https://doi.org/10.1016/S0176-1617(11)81192-2

Xu J, Tian YS, Peng RH, Xiong AS, Zhu B, Jin XF, Yao QH (2010). AtCPK6, a functionally redundant and positive regulator involved in salt/drought stress tolerance in Arabidopsis. Planta 231(6):1251-1260. https://doi.org/10.2307/23391490

Xu X, Chen M, Ji J, Xu Q, Qi X, Chen X (2017). Comparative RNA-seq based transcriptome profiling of waterlogging response in cucumber hypocotyls reveals novel insights into the de novo adventitious root primordia initiation. BMC Plant Biology 17(1):1-13. https://doi.org/10.1186/s12870-017-1081-8

Yamauchi T, Watanabe K, Fukazawa A, Mori H, Abe F, Kawaguchi K, Oyanagi A, Nakazono M (2014). Ethylene and reactive oxygen species are involved in root aerenchyma formation and adaptation of wheat seedlings to oxygendeficient conditions. Journal of Experimental Botany 65(1):261-273. https://doi.org/10.1093/jxb/ert371 
Yang F, Wang Y, Wang J, Deng WQ, Liao L, Li M (2011). Different ecophysiological responses between male and female Populus deltoides clones to waterlogging stress. Forest Ecology and Management 262(11):1963-1971. https://doi.org/10.1016/j.foreco.2011.08.039

Yang F, Xu X, Xiao X, Li C (2009). Responses to drought stress in two poplar species originating from different altitudes. Biologia Plantarum 53(3):511-516. https://doi.org/10.1007/s10535-009-0092-1

Yang O, Popova OV, Süthoff U, Lüking I, Dietz KJ, Golldack D (2009). The Arabidopsis basic leucine zipper transcription factor AtbZIP24 regulates complex transcriptional networks involved in abiotic stress resistance. Gene 436(1-2):45-55. https://doi.org/10.1016/j.gene.2009.02.010

Yan K, Zhao S, Cui M, Han G, Wen P (2018). Vulnerability of photosynthesis and photosystem I in Jerusalem artichoke (Helianthus tuberosus L.) exposed to waterlogging. Plant Physiology and Biochemistry 125:239-246. https://doi.org/10.1016/j.plaphy.2018.02.017

Zabalza A, Van-Dongen JT, Froehlich A, Oliver SN, Faix B, Gupta KJ, ... Geigenberger P (2009). Regulation of respiration and fermentation to control the plant internal oxygen concentration. Plant Physiology 149(2):1087-1098. https://doi.org/10.1104/pp.108.129288

Zhang Q, Huber H, Beljaars SJ, Birnbaum D, de Best S, de Kroon H, Visser EJ (2017). Benefits of flooding-induced aquatic adventitious roots depend on the duration of submergence: linking plant performance to root functioning. Annals of Botany 120(1):171-180. https://doi.org/10.1093/aob/mcx049

Zhou Z, Li G, Sun X, Xu F, Chen Z (2019). Physiological responses and tolerance evaluation of five poplar varieties to waterlogging. Notulae Botanicae Horti Agrobotanici Cluj-Napoca 47(3):658-667. https://doi.org/10.15835/nbha47311440

Zhu X, Li X, Jiu S, Zhang K, Wang C, Fang J (2018). Analysis of the regulation networks in grapevine reveals response to waterlogging stress and candidate gene-marker selection for damage severity. Royal Society Open Science 5(6):172253. https://doi.org/10.1098/rsos.172253
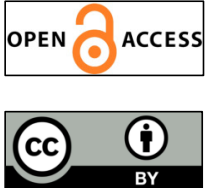

The journal offers free, immediate, and unrestricted access to peer-reviewed research and scholarly work. Users are allowed to read, download, copy, distribute, print, search, or link to the full texts of the articles, or use them for any other lawful purpose, without asking prior permission from the publisher or the author.

License - Articles published in Notulae Botanicae Horti Agrobotanici Cluj-Napoca are Open-Access, distributed under the terms and conditions of the Creative Commons Attribution (CC BY 4.0) License. (C) Articles by the authors; UASVM, Cluj-Napoca, Romania. The journal allows the author(s) to hold the copyright/to retain publishing rights without restriction. 
Supplementary files

(A)

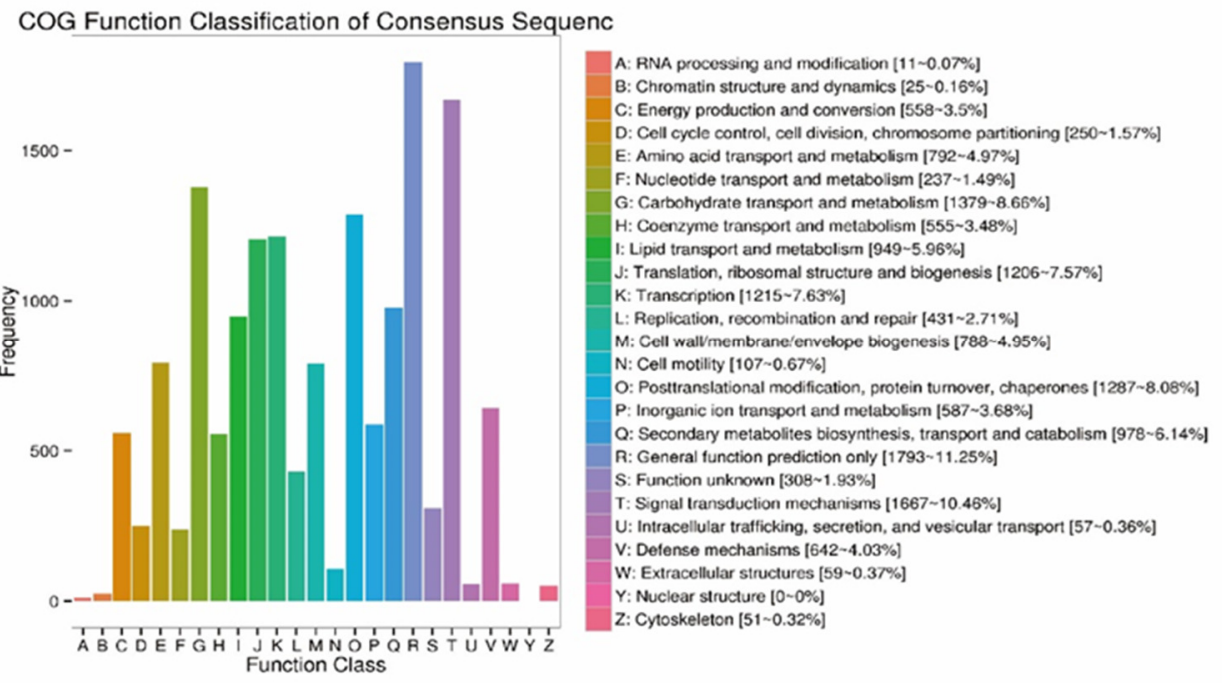

(B)

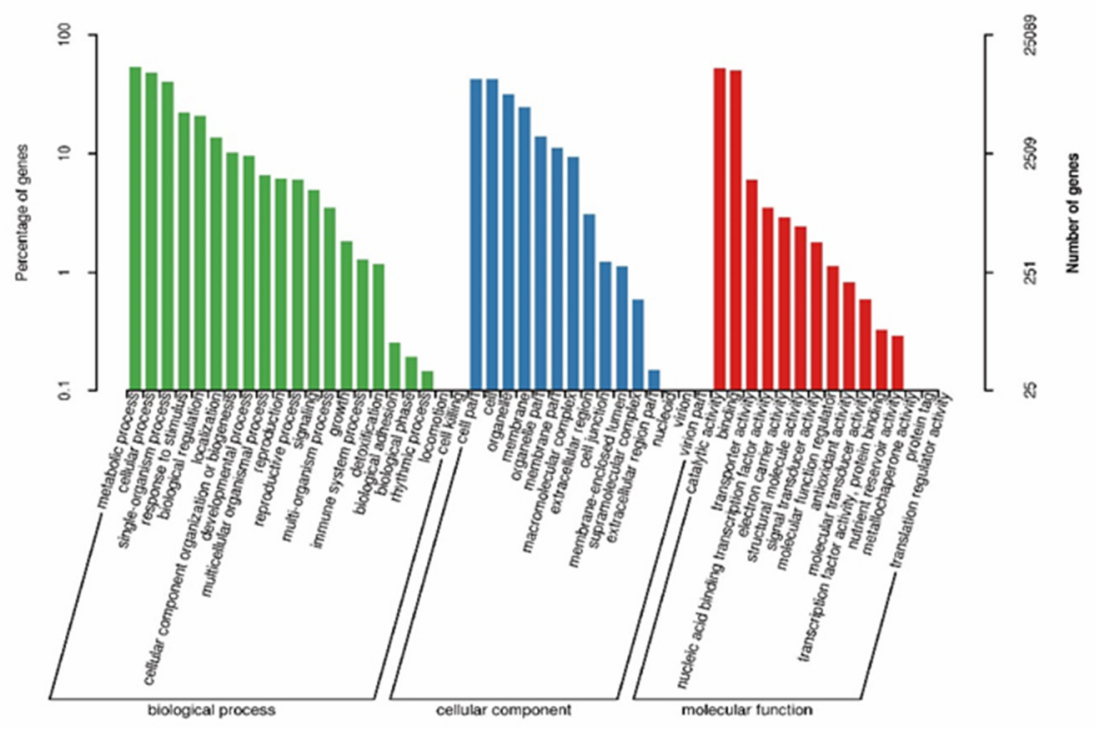

Supplementary Figure 1. Functional annotations of the genes of the $P$. deltoides 'DHY' transcriptome. (A) COG function annotation of $P$. deltoides 'DHY'. (B) GO function annotation of the P. deltoides 'DHY' 
Table S1. Evaluation of sample sequencing data

\begin{tabular}{|c|c|c|c|c|}
\hline Sample & $\begin{array}{c}\text { Raw Reads } \\
\text { Number }\end{array}$ & $\begin{array}{c}\text { Clean Reads } \\
\text { Number }\end{array}$ & $\begin{array}{c}\text { Clean Bases } \\
\text { Number }\end{array}$ & $\begin{array}{c}\text { Clean Q30 Bases Rate } \\
(\%)\end{array}$ \\
\hline DPL-C1 & $51,929,190$ & $25,964,595$ & $7,774,594,844$ & $94.04 \%$ \\
\hline DPL-C2 & $47,613,326$ & $23,806,663$ & $7,129,139,516$ & $94.40 \%$ \\
\hline DPL-C3 & $49,801,650$ & $24,900,825$ & $7,454,586,852$ & $94.52 \%$ \\
\hline DPL-F1 & $51,783,350$ & $25,891,675$ & $7,754,200,044$ & $94.22 \%$ \\
\hline DPL-F2 & $48,063,712$ & $24,031,856$ & $7,197,184,472$ & $93.95 \%$ \\
\hline DPL-F3 & $50,993,140$ & $25,496,570$ & $7,635,069,922$ & $94.12 \%$ \\
\hline DPR-C1 & $46,403,720$ & $23,201,860$ & $6,949,765,240$ & $94.00 \%$ \\
\hline DPR-C2 & $51,309,390$ & $25,654,695$ & $7,682,147,762$ & $93.98 \%$ \\
\hline DPR-C3 & $49,371,936$ & $24,685,968$ & $7,387,084,744$ & $94.20 \%$ \\
\hline DPR-F1 & $41,699,682$ & $20,849,841$ & $6,246,727,830$ & $93.94 \%$ \\
\hline DPR-F2 & $42,713,406$ & $21,356,703$ & $6,396,510,758$ & $94.55 \%$ \\
\hline DPR-F3 & $42,880,856$ & $21,440,428$ & $6,420,303,954$ & $94.32 \%$ \\
\hline
\end{tabular}

Table S2. Genes splicing length result statistics table

\begin{tabular}{|c|c|c|}
\hline length range & Count & Percentage (\%) \\
\hline $200-400$ & 4435 & 10.55 \\
\hline $400-600$ & 3890 & 9.25 \\
\hline $600-1000$ & 6835 & 16.26 \\
\hline $1000-2000$ & 13146 & 31.28 \\
\hline $2000-3000$ & 7413 & 17.64 \\
\hline $3000-4000$ & 3627 & 8.63 \\
\hline $4000+$ & 2751 & 6.55 \\
\hline Total & 42569 & \\
\hline Length of N50 & 2458 & \\
\hline Average length & 1731.64 & \\
\hline
\end{tabular}

Table S3. Functional annotations of Genes in the NR, NT, Swiss-Prot, PFAM, COG, GO and KEGG databases

\begin{tabular}{|c|c|c|c|c|c|c|c|c|}
\hline Database & NR & KOG & Swiss-Prot & PFAM & COG & GO & KEGG & eggNOG \\
\hline Count & 42017 & 20765 & 29154 & 398 & 14329 & 25089 & 12982 & 33486 \\
\hline Percentage & $99.98 \%$ & $49.41 \%$ & $69.37 \%$ & $0.95 \%$ & $34.10 \%$ & $59.70 \%$ & $30.89 \%$ & $79.68 \%$ \\
\hline
\end{tabular}

